\title{
Effect of Sn Substitution on the Thermoelectric Properties of Synthetic Tetrahedrite
}

Sahil Tippireddy, ${ }^{\dagger}$ D. S. Prem Kumar, ${ }^{\dagger}$ Anirudha Karati, ${ }^{\S}$ Anbalagan Ramakrishnan, ${ }^{\perp}$ Shreya Sarkar,, Sebastian C. Peter, ${ }^{\#, \nabla}$ P. Malar, Kuei-Hsien Chen, ${ }^{\perp}$ B. S. Murty, and Ramesh Chandra Mallik ${ }^{*}{ }^{\dagger}{ }^{\dagger}$

${ }^{\dagger}$ Thermoelectric Materials and Devices Laboratory, Department of Physics, Indian Institute of Science, Bangalore 560012, India

${ }^{\ddagger}$ Research Institute, Department of Physics and Nanotechnology, SRM University, Kattankulathur 603203, India

${ }^{\S}$ Department of Chemistry and "Department of Metallurgical and Materials Engineering, Indian Institute of Technology, Chennai 600036, India

${ }^{\perp}$ Institute of Atomic and Molecular Sciences, Academia Sinica, No. 1, Section 4, Roosevelt Road, Taipei 10617, Taiwan

${ }^{\#}$ New Chemistry Unit and ${ }^{\nabla}$ School of Advanced Materials, Jawaharlal Nehru Centre for Advanced Scientific Research, Bangalore 560064, India

\section{Supporting Information}

ABSTRACT: The present study reports the effect of $\mathrm{Sn}$ substitution on the structural and thermoelectric properties of synthetic tetrahedrite $\left(\mathrm{Cu}_{12} \mathrm{Sb}_{4} \mathrm{~S}_{13}\right)$ system. The samples were prepared with the intended compositions of $\mathrm{Cu}_{12} \mathrm{Sb}_{4-x} \mathrm{Sn}_{x} \mathrm{~S}_{13}$ $(x=0.25,0.35,0.5,1)$ and sintered using spark plasma sintering. A detailed structural characterization of the samples revealed tetrahedrite phase as the main phase with $\mathrm{Sn}$ substituting at both $\mathrm{Cu}$ and $\mathrm{Sb}$ sites instead of only $\mathrm{Sb}$ site.
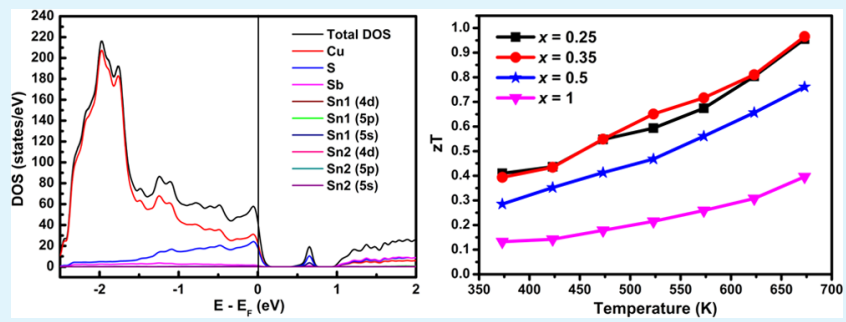
The theoretical calculations using density functional theory revealed that $\mathrm{Sn}$ at $\mathrm{Cu}(1) 12 \mathrm{~d}$ or $\mathrm{Cu}(2) 12 \mathrm{e}$ site moves the Fermi level $\left(E_{\mathrm{F}}\right)$ toward the band gap, whereas $\mathrm{Sn}$ at $\mathrm{Sb} 8 \mathrm{c}$ site introduces hybridized hole states near $E_{\mathrm{F}}$. Consequently, a relatively high optimum power factor of $1.3 \mathrm{~mW} / \mathrm{mK}^{2}$ was achieved by the $x=0.35$ sample. The Sn-substituted samples exhibited a significant decrease in the total thermal conductivity $\left(\kappa_{\mathrm{T}}\right)$ compared to the pristine composition $\left(\mathrm{Cu}_{12} \mathrm{Sb}_{4} \mathrm{~S}_{13}\right)$, primarily because of reduced electronic thermal conductivity. Due to an optimum power factor $\left(1.3 \mathrm{~mW} / \mathrm{mK}^{2}\right)$ and reduced thermal conductivity $(0.9 \mathrm{~W} / \mathrm{mK})$, a maximum $z T$ of 0.96 at $673 \mathrm{~K}$ was achieved for $x=0.35$ sample, which is nearly $40 \%$ increment compared to that of the pristine $\left(\mathrm{Cu}_{12} \mathrm{Sb}_{4} \mathrm{~S}_{13}\right)$ sample.

KEYWORDS: tetrahedrite, X-ray diffraction (XRD), X-ray photoelectron spectroscopy (XPS), density functional theory (DFT), thermoelectric properties

\section{INTRODUCTION}

Thermoelectric generators (TEGs) are important candidates for providing reliable and sustainable source of energy. The primary advantage of using TEGs to convert heat energy to electrical energy is that they do not involve carbon emissions unlike conventional engines/generators that utilize fossil fuels. But the thermoelectric materials employed in these TEGs have limited conversion efficiency, which is dependent on a quantity called thermoelectric figure of merit $(z T)$ given by

$$
z T=\frac{S^{2}}{\rho \kappa_{\mathrm{T}}} T
$$

where $S, \rho, \kappa_{\mathrm{T}}$, and $T$ denote the Seebeck coefficient, electrical resistivity, total thermal conductivity (consisting of lattice $\kappa_{\mathrm{L}}$ and electronic $\kappa_{\mathrm{e}}$ components), and the absolute temperature, respectively. It can be seen from eq 1 that for a high $z T, S$ should be large while $\rho$ and $\kappa_{\mathrm{T}}$ should be kept low. But since $S$ and $\rho$ are interdependent on each other via charge carrier concentration $n$, increasing/decreasing one quantity will affect the other. One way of achieving an optimum power factor (PF) $\left(S^{2} / \rho\right)$ is to introduce a dopant $(\mathrm{s}) /$ substituent(s) in the system, which can optimize $n$ and result in an optimum ratio of $S^{2} / \rho$. Simultaneously, $\kappa_{\mathrm{L}}$ can be reduced via phonon scattering induced by the dopant/substituent atom. Consequently, $z T$ can be enhanced via doping or substitution methods. Conventional state-of-the-art materials such as $\mathrm{PbTe}{ }^{1,2}$ $\mathrm{Bi}_{2} \mathrm{Te}_{3}{ }^{3}$, and $\mathrm{SnSe} \mathrm{e}^{4,5}$ have shown reasonably high $z \mathrm{~T}$ at room temperature to mid-temperature range based on various doping/substitution schemes. But unfortunately, they contain toxic, costly, or rare elements, which may not be viable for large-scale commercial use. In this context, tetrahedrites $\left(\mathrm{Cu}_{12} \mathrm{Sb}_{4} \mathrm{~S}_{13}\right)$ have received a lot of interest due to its abundant, toxic-free constituents and a relatively high thermoelectric performance in the mid-temperature range (500-700 K). ${ }^{6,7}$

Received: February 16, 2019

Accepted: May 23, 2019

Published: May 23, 2019 
Tetrahedrites with nominal composition of $\mathrm{Cu}_{12} \mathrm{Sb}_{4} \mathrm{~S}_{13}$ are p-type degenerate semiconductors possessing low electrical resistivity $\left(0.012 \mathrm{~m} \Omega \mathrm{m}\right.$ at $\left.673 \mathrm{~K}^{8}\right)$ and moderate Seebeck coefficient $\left(134 \mu \mathrm{V} / \mathrm{K}\right.$ at $\left.673 \mathrm{~K}^{8}\right)$ due to high density of states (DOS) near Fermi level $\left(E_{\mathrm{F}}\right)$. It was found that introducing divalent/trivalent substituent at $\mathrm{Cu}^{1+} 12 \mathrm{~d}$ tetrahedral site (such as transition metals) leads to hole compensation, resulting in optimization of the power factor and electronic thermal conductivity. ${ }^{6-8}$ A high $z T$ of 1 was obtained at $720 \mathrm{~K}$ for the composition $\mathrm{Cu}_{11} \mathrm{Zn}_{1} \mathrm{Sb}_{4} \mathrm{~S}_{13},{ }^{6}$ and 0.98 for $\mathrm{Cu}_{11.5} \mathrm{Co}_{0.5} \mathrm{Sb}_{4} \mathrm{~S}_{13}$ $(\text { at } 673 \mathrm{~K})^{8}$ among transition-metal substituted tetrahedrites. A similar approach was explored by substituting $\mathrm{Te}$ at the $\mathrm{Sb}$ site,

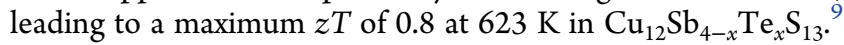
It was also observed that double substitution at $\mathrm{Cu}, \mathrm{Sb}$ or $\mathrm{Cu}, \mathrm{S}$ sites can be useful in having dual control of the thermoelectric properties. A maximum $z T$ of 0.8 was obtained for the sample $\mathrm{Cu}_{12-x} \mathrm{Co}_{x} \mathrm{Sb}_{4-y} \mathrm{Te}_{y} \mathrm{~S}_{13}$ at $673 \mathrm{~K}$ with $x, y=0.82,0.41 .^{10}$ Among the $\mathrm{Cu}_{12-x} \mathrm{M}_{x} \mathrm{Sb}_{4-y} \mathrm{Te}_{y} \mathrm{~S}_{13}(\mathrm{M}=\mathrm{Zn}, \mathrm{Ni})$ compositions, the highest $z T$ of 0.7 was shown by the composition $\mathrm{Cu}_{11.5} \mathrm{Ni}_{0.5} \mathrm{Sb}_{3.25} \mathrm{Te}_{0.75} \mathrm{~S}_{13}$ at $673 \mathrm{~K}^{11}$ Further, the effect of double substitution in tetrahedrite with a divalent substituent $(\mathrm{Zn})$ at $\mathrm{Cu}$ site and isovalent substituent $(\mathrm{Se})$ at $\mathrm{S}$ site was explored. It was found that the combined effect of $\mathrm{Zn}$ and Se double substitution in tetrahedrite resulted in simultaneous optimization of power factor and thermal conductivity. Consequently, a high $z T$ of 0.86 was achieved for the $\mathrm{Cu}_{11} \mathrm{Zn}_{1} \mathrm{Sb}_{4} \mathrm{~S}_{12.75} \mathrm{Se}_{0.25}$ sample at $673 \mathrm{~K}^{12}$

In a recent report, $S$ n-substituted tetrahedrite samples with formula $\mathrm{Cu}_{12-x} \mathrm{Sn}_{x} \mathrm{Sb}_{4} \mathrm{~S}_{13}(x=0-0.6)$ were prepared, ${ }^{13}$ where it was reported that $\mathrm{Sn}^{4+}$ at $\mathrm{Cu}$ site leads to hole compensation and optimization of the thermoelectric parameters. As a result, a maximum $z T$ of 0.65 at $665 \mathrm{~K}$ was obtained for the compositions $x=0.3-0.5 .^{13}$ Another recent study by Nasonova et al. ${ }^{14}$ involving high-resolution powder X-ray diffraction (XRD) and Mössbauer spectroscopy reported that $\mathrm{Sn}$ in $\mathrm{Cu}_{12-x} \mathrm{Sn}_{x} \mathrm{Sb}_{4} \mathrm{~S}_{13}$ substitutes at $\mathrm{Cu}(1)$ 12d site and exhibits a +4 oxidation state. ${ }^{14}$ Previously, however, Hansen et al. ${ }^{15}$ performed a detailed study involving $\mathrm{Sn}$ substitution at $\mathrm{Cu}$ and $\mathrm{Sb}$ sites in tetrahedrite. It was reported that $\mathrm{Sn}$ can also exhibit a valence state of +2 and can be substituted at $\mathrm{Sb}$ site. Hence, there was further scope of studying Sn substitution in the tetrahedrite system. In the present study, our motivation, therefore, was to initially explore $\mathrm{Sn}$ substitution at $\mathrm{Sb}$ site and investigate its effect on the thermoelectric properties. But a detailed structural characterization using XRD, electron probe microanalysis (EPMA), X-ray photoelectron spectroscopy (XPS), and Mössbauer spectroscopy revealed that Sn might be substituting at both $\mathrm{Cu}(2) 12 \mathrm{e}$ and $\mathrm{Sb} 8 \mathrm{c}$ sites instead of only $\mathrm{Sb} 8 \mathrm{c}$ site. And thus, a kind of double substitution was observed in the substituted samples, which is explained based on characterization results, theoretical analysis, and transport property measurements.

\section{EXPERIMENTAL SECTION}

The starting elements: $\mathrm{Cu}, \mathrm{S}, \mathrm{Sb}(\sim 5 \mathrm{~N})$, and $\mathrm{Sn}(\sim 4 \mathrm{~N})$ were weighed together in stoichiometric ratio, transferred to quartz ampoules, and sealed under a dynamic vacuum of $\sim 10^{-4}$ mbar. The sealed ampoules were first heated to $973 \mathrm{~K}$ and soaked for $3 \mathrm{~h}$. The furnace was then slowly cooled down to $823 \mathrm{~K}$ in $30 \mathrm{~h}$. After reaching $823 \mathrm{~K}$, the ampoules were cooled down to room temperature by switching off the furnace. The as-cast ingots were ground into fine powder using an agate mortar and pestle. The fine powders were then cold-pressed to form pellets and annealed in evacuated quartz tubes at $773 \mathrm{~K}$ for $48 \mathrm{~h}$. The annealed pellets were again ground into a fine powder and ball-milled using Fritsch Pulverisette P7 planetary mill at $300 \mathrm{rpm}$ for $3 \mathrm{~h}$. The milling was done in a toluene medium with a ball-to-powder mass ratio of 10:1. The ball-milled powders were then sintered using spark plasma sintering (SPS) at $753 \mathrm{~K}$ for $10 \mathrm{~min}$ under a pressure of $70 \mathrm{MPa}$. The SPS was carried out using Dr. Sinter SPS625 system. The densities $\left(d_{s}\right)$ of all of the Sn-substituted samples (obtained using Archimedes' principle) were found to be $\geq 98 \%$ of the theoretical density. The sintered pellets were cut into $\sim 10 \times 2 \times 2$ $\mathrm{mm}^{3}$ cuboids for Seebeck coefficient and electrical resistivity measurements. For thermal diffusivity measurements, circular disks of $\sim 6 \mathrm{~mm}$ diameter and $\sim 1 \mathrm{~mm}$ thickness were cut from the same sintered pellets. The powder XRD of the samples was done on a Rigaku SmartLab X-ray diffractometer with $\mathrm{Cu} \mathrm{K} \alpha(\lambda=1.5418 \AA)$ radiation as the X-ray source. The Rietveld refinement of the XRD patterns was performed using FullProf software ${ }^{16}$ to determine the crystal structure and phases, and evaluate the lattice parameters. A Jeol JXA-8530F electron probe microanalyzer equipped with a wavelength-dispersive spectroscope was used to perform the compositional analysis and obtain the microstructures. X-ray photoelectron spectroscopy (XPS) of the Sn-substituted samples was performed on a Prevac UHV XPS system with $\mathrm{Al} \mathrm{K \alpha}$ as the excitation source. The room-temperature transmission ${ }^{119} \mathrm{Sn}$ Mössbauer spectra of $\mathrm{Cu}_{12} \mathrm{Sb}_{4-x} \mathrm{Sn}_{x} \mathrm{~S}_{13}(x=0.5$ and 1$)$ were recorded with a Mössbauer spectrometer operating in a constant acceleration mode and equipped with $\mathrm{Ca}^{119 \mathrm{~m}} \mathrm{SnO}_{3}$ (from Ritverc products) as the source of $\gamma$-rays. An amount of $10 \mathrm{mg}$ of the sample was loaded in a sample holder and data collection was done over a period of $192 \mathrm{~h}$. The Mössbauer data were acquired using Wissoft CMCA-550 module in the Multichannel Scaling window. The obtained Mössbauer spectrum was fitted using Lorentzian line shapes with the WinNormos for IGOR Pro software package based on the least-squares method. All isomer shifts are referred to $\mathrm{CaSnO}_{3}$ at $300 \mathrm{~K}$. The electrical resistivity and Seebeck coefficients of the samples were measured using a Linsies LSR-3 system. The total thermal conductivity was obtained using the formula $\kappa_{\mathrm{T}}=D d_{\mathrm{s}} C_{\mathrm{p}}$, where $D$ is the thermal diffusivity, $d_{\mathrm{s}}$ the sample density, and $C_{\mathrm{p}}$ the specific heat capacity. The thermal diffusivity was obtained using a Netzsch LFA 457 laser flash system and $C_{\mathrm{p}}$ was considered as $0.43 \mathrm{~J} /(\mathrm{g} \mathrm{K})$, which is the Dulong-Petit value of tetrahedrite. The measurement errors for electrical resistivity, Seebeck coefficient, and thermal conductivity are 10,7 , and $6 \%$, respectively.

\section{THEORETICAL CALCULATION DETAILS}

The theoretical calculations using density functional theory (DFT) were done with the Quantum Espresso ${ }^{17}$ code using the generalized gradient approximation exchange-correlation functional given by Perdew, Burke, and Ernzerhof. ${ }^{18}$ An energy cutoff of $475 \mathrm{eV}$ for plane-wave expansion was taken with a Monkhorst-Pack $k$-point grid of $7 \times 7 \times 7$. The crystal structure was considered as a body-centered cubic unit cell containing 58 atoms per unit cell with a lattice parameter of $10.33 \AA$. The $\mathrm{Sn}$ atom was substituted at $\mathrm{Cu}(1) 12 \mathrm{~d}$ site, $\mathrm{Cu}(2) 12 \mathrm{e}$ site, $\mathrm{Sb} 8 \mathrm{c}$ site, and also at both $\mathrm{Cu}(1) / \mathrm{Cu}(2)$ and $\mathrm{Sb}$ sites. The atomic coordinates of the elements in the unit cell were relaxed in each case until the forces on the atoms were less than $0.01 \mathrm{eV} / \AA$. The projected density of states (PDOS) was evaluated for each case to understand the electronic structure in $\mathrm{Sn}$-substituted tetrahedrite.

\section{RESULTS AND DISCUSSION}

4.1. X-ray Diffraction (XRD). Figure 1 displays the XRD patterns of all of the substituted samples indexed with ICDD PDF \# 00-024-1318 tetrahedrite phase. The XRD patterns revealed that all of the samples have tetrahedrite phase as the major phase with secondary phase peaks corresponding to $\mathrm{Cu}_{3} \mathrm{SbS}_{4}$ in all of the samples, marked in Figure 1. For $x=1.5$ sample, peaks corresponding to $\mathrm{Cu}_{4} \mathrm{SnS}_{4}$ secondary phase were 


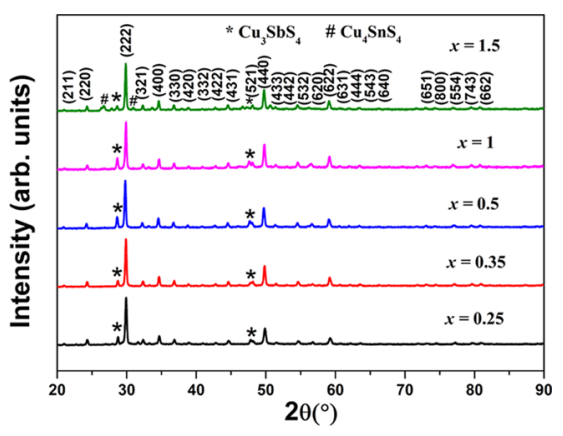

Figure 1. XRD patterns of the samples $(x=0.25,0.35,0.5,1,1.5)$ indexed with the tetrahedrite phase.

also found. The Rietveld refinement of the XRD patterns was performed to extract the phase information and determine the lattice parameters. Interestingly, the Rietveld analysis revealed that $\mathrm{Sn}$ could be substituted at many possible sites, i.e., $\mathrm{Cu}(1)$, $\mathrm{Cu}(2), \mathrm{Sb}$, or both $\mathrm{Cu}(1) / \mathrm{Cu}(2)$ and $\mathrm{Sb}$ simultaneously. Tables S1 and S2 of the Supporting Information show the refinement parameters of the Rietveld analysis considering all possible sites for the samples $x=0.25$ and 1 , respectively. It was observed that the refinement parameters converged almost similarly for each case, with a slightly better convergence for the case when $\mathrm{Sn}$ substitutes at both $\mathrm{Cu} 12 \mathrm{~d} / 12 \mathrm{e}$ and $\mathrm{Sb} 8 \mathrm{c}$ sites. For instance, the $R_{\text {Bragg }}$ for the case when $S n$ is substituted at both $\mathrm{Cu}(2) 12 \mathrm{e}$ and $\mathrm{Sb}$ sites is lower by $36 \%$ compared to the case when $\mathrm{Sn}$ substitutes at only $\mathrm{Cu}(1) 12 \mathrm{~d}$, and lower by $31 \%$ when $\mathrm{Sn}$ substitutes at only $\mathrm{Cu}(2) 12 \mathrm{e}$ and by about $13 \%$ when $\mathrm{Sn}$ is substituted at only $\mathrm{Sb}$ site. This implies the possibility of $\mathrm{Sn}$ double substitution at both $\mathrm{Cu}(1) / \mathrm{Cu}(2)$ and $\mathrm{Sb}$ sites. It was observed that among the $\mathrm{Cu}(1) 12 \mathrm{~d}$ and $\mathrm{Cu}(2)$ $12 \mathrm{e}$ sites, the refinement converges better for $\mathrm{Sn}$ substitution at $\mathrm{Cu}(2) 12 \mathrm{e}$ site or both $\mathrm{Cu}(2) 12 \mathrm{e}$ and $\mathrm{Sb}$ sites. Figures $\mathrm{S} 1-\mathrm{S} 5$ of the Supporting Information display the refined XRD patterns for all of the samples considering $S n$ substitution at both $\mathrm{Cu}(2) 12 \mathrm{e}$ and $\mathrm{Sb} 8 \mathrm{c}$ sites. The refined XRD pattern for $x$ $=0.35$ sample is also shown in Figure 2 with the inset depicting

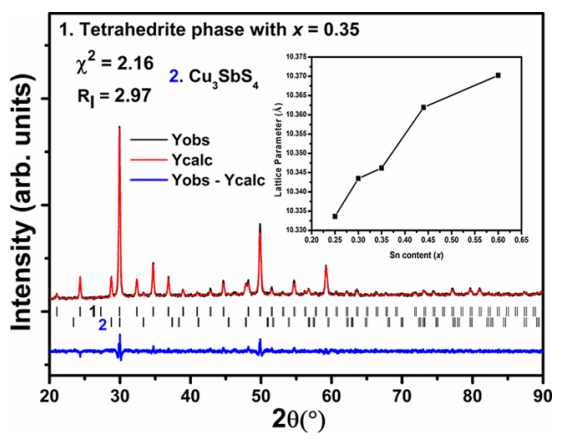

Figure 2. Refined XRD pattern for $x=0.35$ sample The inset shows the variation of lattice parameter with $S n$ content $(x=0.25,0.35,0.5$, $1,1.5)$ calculated considering $\mathrm{Sn}$ substitution at both $\mathrm{Cu}(2) 12 \mathrm{e}$ and $\mathrm{Sb} 8 \mathrm{c}$ sites.

the lattice parameter as a function of $x$ (calculated using Rietveld analysis for the case when $S n$ substitutes at both $\mathrm{Cu}(2) 12 \mathrm{e}$ and $\mathrm{Sb} 8 \mathrm{c}$ sites), where the $x$ values ( $\mathrm{Sn}$ content) were taken from the EPMA results. The secondary phase quantified using Rietveld analysis is given in Supporting Information, which shows $\mathrm{Cu}_{3} \mathrm{SbS}_{4}$ vol \% ranging from 6 to
$12 \%$ in the substituted samples. The vol \% of $\mathrm{Cu}_{4} \mathrm{SnS}_{4}$ in $x=$ 1.5 sample was found to be around $15 \%$ from Rietveld analysis.

From Figure 2, it was observed that the lattice parameter increased with increase in $\mathrm{Sn}$ concentration. This indicates successful substitution of $S n$ in the tetrahedrite system, with $\mathrm{Sn}^{4+}(0.69 \AA)$ and $\mathrm{Sn}^{2+}(1.18 \AA)$, both having larger ionic radii than $\mathrm{Cu}^{1+} / \mathrm{Cu}^{2+}(0.6 / 0.57 \AA)$ and $\mathrm{Sb}^{3+}(0.76 \AA) .{ }^{15,19,20}$ But the trend of lattice parameter versus $x$ is not linear, which could be due to the secondary phase(s) in the samples and/or defects due to Sn substitution. Another reason for the nonlinear lattice parameter could be the partial substitution of $\mathrm{Sn}$ at both $\mathrm{Cu}(2)$ and $\mathrm{Sb}$ sites, as shown by Rietveld analysis. It was observed by Hansen et al. that $\mathrm{Sn}^{4+}$ is incorporated at the $\mathrm{Cu}$ site in tetrahedrite when no other divalent transition metal is present in the system. ${ }^{15}$ But it was also reported that $\mathrm{Sn}^{2+}$ also has a high success rate in substituting at the $\mathrm{Sb}$ site. ${ }^{15}$ It can therefore be concluded that a kind of double substitution might be taking place in the samples with Sn existing in mixed valence states of +4 and +2 substituting at both $\mathrm{Cu}(2)$ and $\mathrm{Sb}$ sites, respectively. This was also confirmed by X-ray photoelectron spectroscopy (XPS) and Mössbauer spectroscopy discussed in Sections 4.3 and 4.5, respectively. However, previous studies have shown that $\mathrm{Cu}_{12-x} \mathrm{Sn}_{x} \mathrm{Sb}_{4} \mathrm{~S}_{13}$ series did not show $\mathrm{Sn}$ substitution at $\mathrm{Sb}$ site based on Rietveld refinements. ${ }^{13,14}$ The reason for this discrepancy could be the inherent $\mathrm{Sb}$ deficiency in the present series because our intended compositions were $\mathrm{Cu}_{12} \mathrm{Sb}_{4-x} \mathrm{Sn}_{x} \mathrm{~S}_{13}$ with $\mathrm{Sb}$ added in deficiency to accommodate $\mathrm{Sn}$ substitution at $\mathrm{Sb}$ site. In conclusion, the XRD analysis reveals successful substitution of $\mathrm{Sn}$ in tetrahedrite with the possibility of $\mathrm{Sn}$ substituting at both $\mathrm{Cu}(2) 12 \mathrm{e}$ and $\mathrm{Sb}$ sites.

4.2. Electron Probe Microanalysis (EPMA). The phases of all of the samples quantified using electron probe microanalysis (EPMA) are tabulated in Table 1, and the

Table 1. Nominal and Observed Compositions from EPMA for Primary and Secondary Phases

$\begin{array}{ccc}\begin{array}{c}\text { Se content } \\ \text { (nominal) }\end{array} & \begin{array}{c}\text { observed EPMA } \\ \text { composition for main } \\ \text { phase }\end{array} & \begin{array}{c}\text { observed EPMA composition } \\ \text { for secondary phase }\end{array} \\ x=0.25 & \mathrm{Cu}_{11.22} \mathrm{Sb}_{3.89} \mathrm{Sn}_{0.25} \mathrm{~S}_{13} & \mathrm{Cu}_{3} \mathrm{Sb}_{0.85} \mathrm{Sn}_{0.15} \mathrm{~S}_{4} \\ x=0.35 & \mathrm{Cu}_{11.21} \mathrm{Sb}_{3.84} \mathrm{Sn}_{0.30} \mathrm{~S}_{13} & \mathrm{Cu}_{3} \mathrm{Sb}_{0.75} \mathrm{Sn}_{0.25} \mathrm{~S}_{4} \\ x=0.5 & \mathrm{Cu}_{11.17} \mathrm{Sb}_{3.85} \mathrm{Sn}_{0.35} \mathrm{~S}_{13} & \mathrm{Cu}_{3} \mathrm{Sb}_{0.63} \mathrm{Sn}_{0.47} \mathrm{~S}_{4} \\ x=1 & \mathrm{Cu}_{11.01} \mathrm{Sb}_{3.82} \mathrm{Sn}_{0.44} \mathrm{~S}_{13} & \mathrm{Cu}_{3} \mathrm{Sb}_{0.1} \mathrm{Sn}_{0.95} \mathrm{~S}_{4} \\ x=1.5 & \mathrm{Cu}_{11.06} \mathrm{Sb}_{3.91} \mathrm{Sn}_{0.6} \mathrm{~S}_{13} & \mathrm{Cu}_{3} \mathrm{Sb}_{0.03} \mathrm{Sn}_{0.97} \mathrm{~S}_{4}, \mathrm{Cu}_{4} \mathrm{SnS}_{4}\end{array}$

${ }^{a}$ Normalized to 13 atoms of $\mathrm{S}$ per formula unit of tetrahedrite $\left(\mathrm{Cu}_{12} \mathrm{Sb}_{4} \mathrm{~S}_{13}\right) .{ }^{b}$ Normalized to four atoms of $\mathrm{S}$ per formula unit of $\mathrm{Cu}_{3} \mathrm{Sb}_{1-y} \mathrm{Sn}_{y} \mathrm{~S}_{4}$.

microstructures are shown in Figure $3 a-e$. All of the samples showed deficient $\mathrm{Sn}$ content compared to the nominal composition, with a maximum solubility of $\sim 0.6$ atoms p.f.u. in the tetrahedrite phase. It was found from EPMA that all of the samples contained the secondary phase of off-stochiometric $\mathrm{Cu}_{3} \mathrm{SbS}_{4}$, with $\mathrm{Sn}$ substituting partially at the $\mathrm{Sb}$ site, which was also confirmed from Mössbauer spectroscopy (Section 4.5). It was also found that $\mathrm{Cu}$ and $\mathrm{Sb}$ concentrations are deficient in the main phase of all of the samples, which might indicate $\mathrm{Sn}$ substitution at both $\mathrm{Cu}$ and $\mathrm{Sb}$ sites. It was observed that this $\mathrm{Sb}$ deficiency was nearly the same in all of the samples (up to $x=1$ ), whereas $\mathrm{Cu}$ deficiency increased with increase in $x$. This could indicate that $S n$ concentration at $\mathrm{Sb}$ in all of the samples is similar (up to $x=1$ ), but it might 

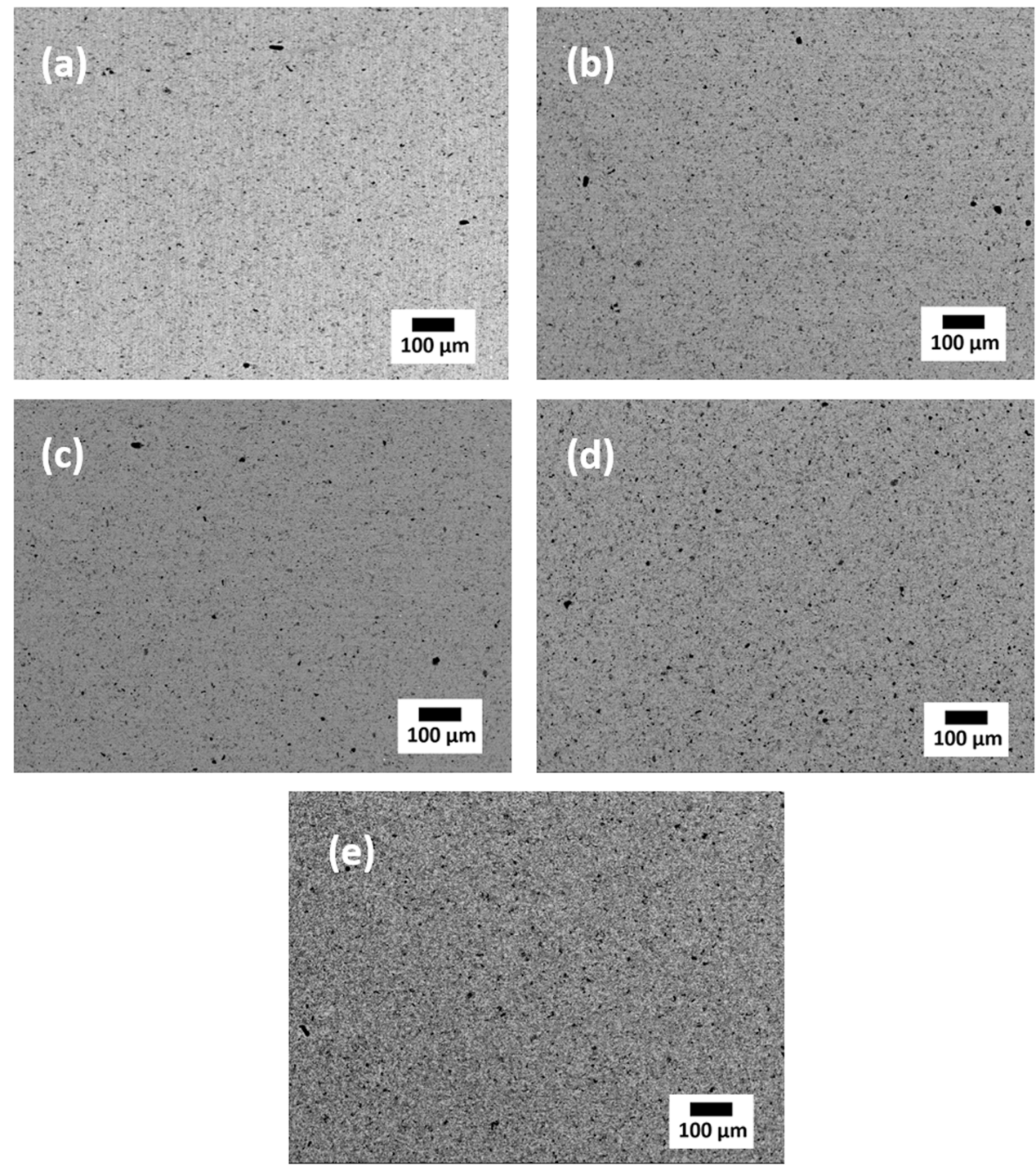

Figure 3. Backscattered electron (BSE) images of (a) $x=0.25$, (b) $x=0.35$, (c) $x=0.5$, (d) $x=1$, and (e) $x=1.5$.

have higher preference for substituting at $\mathrm{Cu}$ site compared to $\mathrm{Sb}$ site for higher concentrations of $\mathrm{Sn}$. For $x=1.5$, it was found that $\mathrm{Sb}$ content is almost approaching the nominal value but $\mathrm{Cu}$ is relatively more deficient, indicating that $\mathrm{Sn}$ might have substituted primarily at $\mathrm{Cu}$ site. This substitution behavior can be understood based on the study by Hansen et al., ${ }^{15}$ where it was observed that solubility of $\mathrm{Sn}$ in tetrahedrite is higher when substituting for metal $(\mathrm{Cu})$ rather than the semimetal $(\mathrm{Sb})$ site. It was found that $\mathrm{Sn}$ at the $\mathrm{Sb}$ site has a higher success rate only when other divalent/trivalent atoms such as $\mathrm{Zn} / \mathrm{Fe}$ were also present at the $\mathrm{Cu}$ site. But in the absence of such divalent/trivalent substituents, $\mathrm{Sn}$ can be easily incorporated at the $\mathrm{Cu}$ site. This is because the tetrahedrite phase is vastly stabilized when two divalent metal atoms per formula unit are added. ${ }^{15}$ Therefore, in the absence of these substituents, $\mathrm{Sn}$ is preferentially substituted at the $\mathrm{Cu}$ site, rather than $\mathrm{Sb}$, which was also observed in the present study. It should be mentioned here that due to the large amount of secondary phase(s) in $x=1.5$ sample, further characterization data and discussion has been excluded from subsequent sections in the manuscript.

4.3. X-ray Photoelectron Spectroscopy (XPS). The Xray photoelectron spectroscopy (XPS) of the $x=0.25$ and 1 samples (Figure 4a,b, respectively) was performed to determine the valence state of the $\mathrm{Sn}$ atoms in the substituted
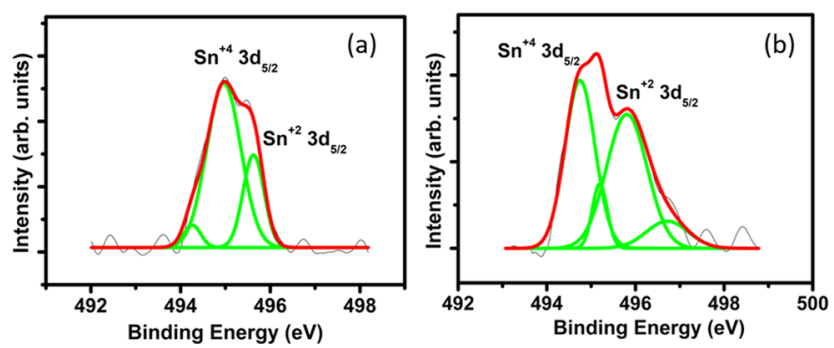

Figure 4. XPS images of the $S n 3 d_{5 / 2}$ lines in (a) $x=0.25$ and (b) $x=$ 1 samples.

samples. The XPS images were calibrated using the C 1s peak at a binding energy (BE) of $284.8 \mathrm{eV}$ referenced from the NIST database. The individual peak assignment corresponding to Sn oxidation states with binding energy is given in Table S4. It can be seen from Figure $4 \mathrm{a}, \mathrm{b}$ that peaks corresponding to both +4 and +2 oxidation states of $S n$ are present in the spectra. It was observed that XPS peak corresponding to $\mathrm{Sn}+4$ 

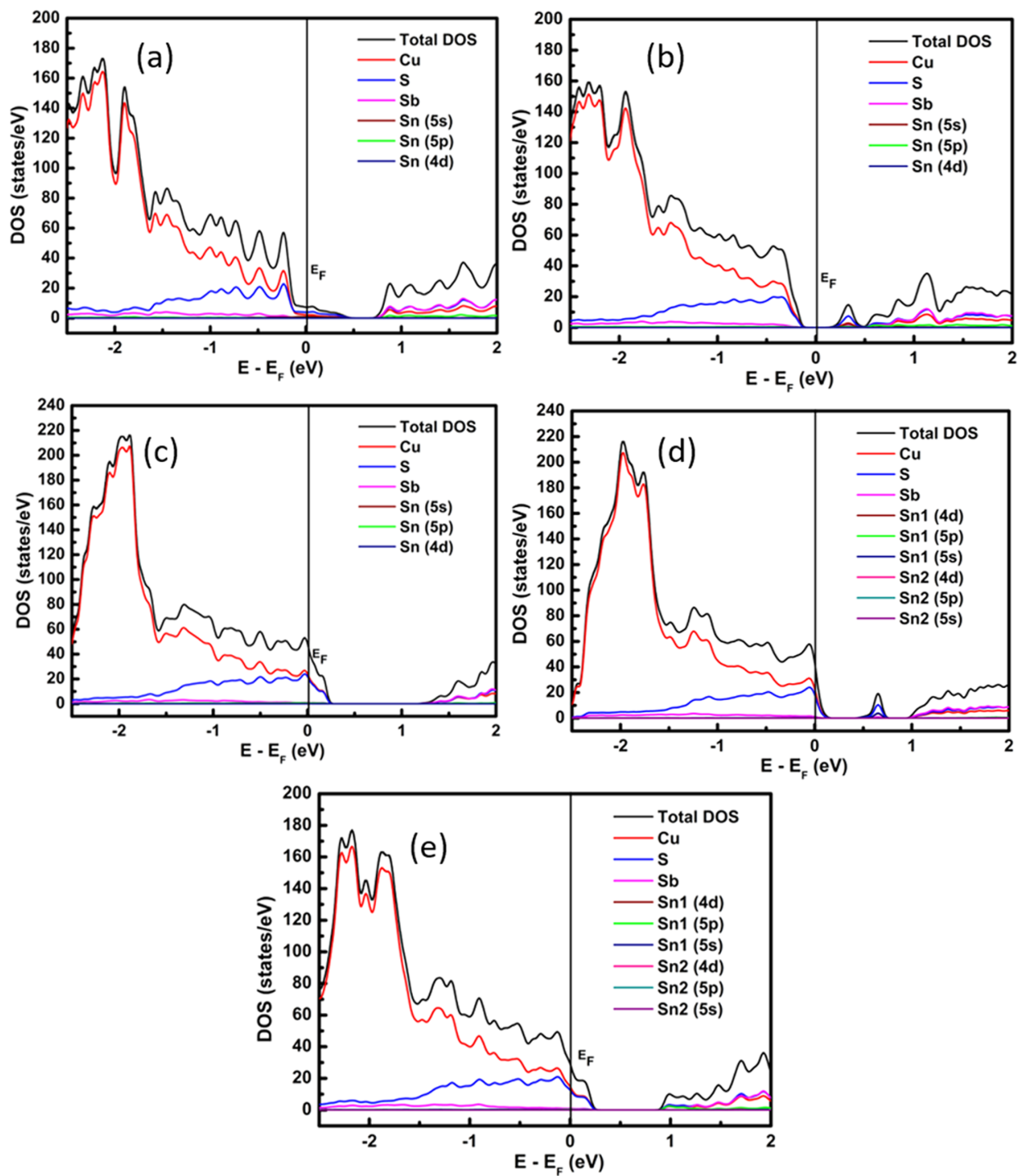

Figure 5. Projected density of states (PDOS) when $\mathrm{Sn}$ is substituted at (a) $\mathrm{Cu}(1) 12 \mathrm{~d}$ in $\mathrm{Cu}_{11} \mathrm{Sn}_{1} \mathrm{Sb}_{4} \mathrm{~S}_{13}$, (b) $\mathrm{Cu}(2) 12 \mathrm{e}$ in $\mathrm{Cu}_{11} \mathrm{Sn}_{1} \mathrm{Sb}_{4} \mathrm{~S}_{13},(\mathrm{c}) \mathrm{Sb}$ $8 \mathrm{c}$ in $\mathrm{Cu}_{12} \mathrm{Sb}_{3} \mathrm{Sn}_{1} \mathrm{~S}_{13}$, (d) both $\mathrm{Cu}(2) 12 \mathrm{e}$ and $\mathrm{Sb} 8 \mathrm{c}$ in $\mathrm{Cu}_{11.5} \mathrm{Sn}_{0.5} \mathrm{Sb}_{3.5} \mathrm{Sn}_{0.5} \mathrm{~S}_{13}$, and (e) both $\mathrm{Cu}(1)$ 12d and $\mathrm{Sb}_{8} \mathrm{c}$ in $\mathrm{Cu}_{11.5} \mathrm{Sn}_{0.5} \mathrm{Sb}_{3.5} \mathrm{Sn}_{0.5} \mathrm{~S}_{13}$. $\mathrm{Sn}_{1}$ and $\mathrm{Sn} 2$ denote $\mathrm{Sn}$ atom at $\mathrm{Cu}(1) 12 \mathrm{~d} / \mathrm{Cu}(2) 12 \mathrm{e}$ and $\mathrm{Sb} 8 \mathrm{c}$ sites, respectively.

was higher in intensity compared to the Sn +2 XPS peak, indicating that $\mathrm{Sn}$ in the tetrahedrite system exists more in the +4 oxidation state. As indicated by the XRD, EPMA, and DFT (Section 4.4) results, $\mathrm{Sn}$ at the $\mathrm{Cu}(2) 12 \mathrm{e}$ site should exhibit +4 oxidation state, whereas $\mathrm{Sn}$ at the $\mathrm{Sb} 8 \mathrm{c}$ site should be in +2 oxidation state. Therefore, in conclusion, the existence of both $\mathrm{Sn}+4$ and +2 oxidation states suggests that $\mathrm{Sn}$ might be substituting at both $\mathrm{Cu}(2) 12 \mathrm{e}$ and $\mathrm{Sb} 8 \mathrm{c}$ sites, with a higher preference for $\mathrm{Cu}(2)$ 12e site (since $\mathrm{Sn}+4$ XPS intensity is higher), which was also confirmed from Mössbauer spectroscopy (Section 4.5) results.

4.4. Theoretical Calculations. To have a qualitative understanding of the electronic structure in Sn-substituted tetrahedrite, DFT calculations were performed for the compositions $\mathrm{Cu}_{11} \mathrm{Sn}_{1} \mathrm{Sb}_{4} \mathrm{~S}_{13}$ ( $\mathrm{Sn}$ at either $12 \mathrm{~d}$ site or $12 \mathrm{e}$ site), $\mathrm{Cu}_{12} \mathrm{Sb}_{3} \mathrm{Sn}_{1} \mathrm{~S}_{13}$ (only $\mathrm{Sb} 8 \mathrm{c}$ site), and $\mathrm{Cu}_{11.5} \mathrm{Sn}_{0.5} \mathrm{Sb}_{3.5} \mathrm{Sn}_{0.5} \mathrm{~S}_{13}$ (both $\mathrm{Cu} 12 \mathrm{~d} / 12 \mathrm{e}$ and $\mathrm{Sb} 8 \mathrm{c}$ sites). Figure $5 \mathrm{a}-\mathrm{e}$ shows the PDOS of the substituted tetrahedrite systems with $\mathrm{Sn}$ at the aforementioned Wycoff positions. It was observed that $\mathrm{Sn}$ at either $\mathrm{Cu} 12 \mathrm{~d}$ or $12 \mathrm{e}$ site (Figure $5 \mathrm{a}, \mathrm{b}$, respectively) moves the Fermi level toward the band gap with negligible states near $E_{\mathrm{F}}$. This is consistent with the picture of $\mathrm{Sn}^{4+}$ substitution at $\mathrm{Cu}^{1+} / \mathrm{Cu}^{2+}$ resulting in effective compensation of holes. On the other hand, $\mathrm{Sn}$ at $\mathrm{Sb}$ site (Figure 5c) creates hybridized hole states near $E_{\mathrm{F}}$ that could indicate $\mathrm{Sn}^{2+}$ substitution at $\mathrm{Sb}^{3+}$ site, which will supply holes to the system. In the case of double-substituted composition $\mathrm{Cu}_{11.5} \mathrm{Sn}_{0.5} \mathrm{Sb}_{3.5} \mathrm{Sn}_{0.5} \mathrm{~S}_{13}$ (Figure $5 \mathrm{~d}, \mathrm{e}$ ), it was observed that a combined effect takes place with $E_{\mathrm{F}}$ moving toward band gap as well as creation of hole states near $E_{\mathrm{F}}$. Consequently, there is a trade-off between the two effects that will ultimately determine the transport properties. In the present series, the XRD, EPMA, and Mössbauer spectroscopy (Section 4.5) results revealed that $S n$ may possibly be substituting at both $\mathrm{Cu}(2) 12 \mathrm{e}$ and $\mathrm{Sb}$ sites with a higher preference for $\mathrm{Cu}(2) 12 \mathrm{e}$ site. The reason for this higher preference could be the fact that $\mathrm{Sn}^{4+}$ at the $\mathrm{Cu}$ site has a filled $4 \mathrm{~d}^{10}$ orbital, which is relatively more stable, compared to $\mathrm{Sn}^{2+}$ at $\mathrm{Sb}$ site, which has a valence electronic configuration of $4 \mathrm{~d}^{10} 5 \mathrm{~s}^{2}$. Because of the $S n$ double substitution, it is expected that the effective charge carrier compensation in the present series will be relatively more subtle compared to the scenario when $S n$ was 
substituting at only $\mathrm{Cu}$ site. This is indeed reflected in the transport properties as explained in subsequent sections.

4.5. Mössbauer Spectroscopy. ${ }^{119} \mathrm{Sn}$ Mössbauer spectra were recorded for $x=0.5$ and 1 compounds. According to Rietveld refinement, although there was a considerable amount of secondary phase in both samples, they were chosen for Mössbauer measurements to obtain high-intensity and goodquality data (since $\mathrm{Sn}$ content is relatively high in these samples). The main aim was to find the oxidation state of Sn, understand the site of Sn substitution in the major phase, and verify the presence of $S n$ in the impurity phase. The Mössbauer spectra of the compounds $\mathrm{Cu}_{11.17} \mathrm{Sb}_{3.85} \mathrm{Sn}_{0.35} \mathrm{~S}_{13}$ and $\mathrm{Cu}_{11.01} \mathrm{Sb}_{3.82} \mathrm{Sn}_{0.44} \mathrm{~S}_{13}$ are shown in Figure 6, and the hyperfine

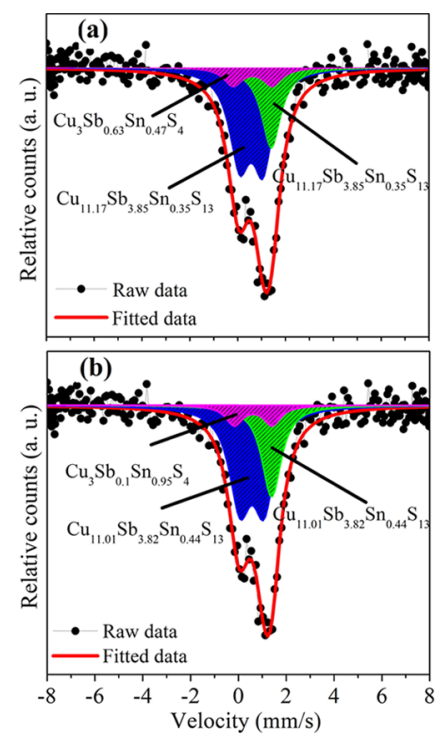

Figure 6. ${ }^{119} \mathrm{Sn}$ Mössbauer spectrum of (a) $\mathrm{Cu}_{11.17} \mathrm{Sb}_{3.85} \mathrm{Sn}_{0.35} \mathrm{~S}_{13}(x=$ $0.5)$ and (b) $\mathrm{Cu}_{11.01} \mathrm{Sb}_{3.82} \mathrm{Sn}_{0.44} \mathrm{~S}_{13}(x=1)$ measured at room temperature.

parameters are tabulated in Table 2. The main component in both the Mössbauer spectra reflects tin in $x=0.5$ and 1 samples. The isomer shift, $\delta=0.55-0.58 \mathrm{~mm} / \mathrm{s}$, corresponding to the main component refers to +4 oxidation state of $\mathrm{Sn}$. The quadrupole splitting is high, $\Delta E_{\mathrm{Q}}=0.98-1 \mathrm{~mm} / \mathrm{s}$, reflecting low symmetry of $\mathrm{Sn}(\mathrm{IV})$ coordination. This could indicate $\mathrm{Sn}^{4+}$ to substitute at the $\mathrm{Cu}(2) 12 \mathrm{e}$ site, which feels an anharmonic potential due to the lone pair of $\mathrm{Sb}$ atoms situated on top and bottom of the trigonal plane. As a result, there is asymmetrical charge distribution around $\mathrm{Sn}$ at the $\mathrm{Cu}(2) 12 \mathrm{e}$ site leading to a high quadrupole splitting. Apart from the main component corresponding to $\mathrm{Sn}^{4+}$, the presence of $\mathrm{Sn}^{2+}$ is also evident in both the samples. The values of the hyperfine parameters are $\delta=1.3-1.4 \mathrm{~mm} / \mathrm{s}$ and $\Delta E_{\mathrm{Q}}=0.02-0.04 \mathrm{~mm} /$ $\mathrm{s}$. The low quadrupole splitting values commensurate relatively higher-symmetry coordination environment around $\mathrm{Sn}$ and validate the assumption that $\mathrm{Sn}^{2+}$ substitutes at the $\mathrm{Sb}$ site, which occupies the $8 \mathrm{c}$ Wyckoff position. Hence, the Mössbauer spectra confirm $\mathrm{Sn}$ to substitute at two different crystallographic sites $(\mathrm{Cu}(2) 12 \mathrm{e}$ and $\mathrm{Sb} 8 \mathrm{c})$ exhibiting two different oxidation states ( +4 and +2 , respectively), consistent with XRD, EPMA, and XPS. It was also found that among the two $\mathrm{Cu}$ sites (12d and 12e), Sn may have a higher preference for $\mathrm{Cu}(2) 12 \mathrm{e}$ site when there is a double-substitution scenario in the tetrahedrite system. We hypothesize a possible reason for this higher preference of $\mathrm{Sn}^{4+}$ to substitute at the $\mathrm{Cu}(2)$ 12e site in the following way: As explained in Section 4.2, the tetrahedrite system has been observed to be stable with compositions having a filled valence band. The DFT calculations (Section 4.4) revealed that $\mathrm{Sn}$ at $\mathrm{Sb} 8 \mathrm{c}$ site introduces hole states, whereas $\mathrm{Sn}$ at $\mathrm{Cu} 12 \mathrm{~d} / 12 \mathrm{e}$ compensates these hole states. It was observed that $\mathrm{Sn}$ substituting at both $\mathrm{Cu}(2) 12 \mathrm{e}$ and $\mathrm{Sb} 8 \mathrm{c}$ (Figure 5d) leads to more effective hole compensation (and hence a more filled valence band) compared to $\mathrm{Sn}$ substituting at $\mathrm{Cu}(1) 12 \mathrm{~d}$ and $\mathrm{Sb} 8 \mathrm{c}$ (Figure $5 e)$. Therefore, $\mathrm{Sn}$ in doubly substituted tetrahedrite occupies $\mathrm{Cu}(2) 12 \mathrm{e}$ and $\mathrm{Sb} 8 \mathrm{c}$ with +4 and +2 oxidation states, respectively.

In addition to the above-mentioned components, the Mössbauer spectra of both $\mathrm{Cu}_{11.17} \mathrm{Sb}_{3.85} \mathrm{Sn}_{0.35} \mathrm{~S}_{13}$ and $\mathrm{Cu}_{11.01} \mathrm{Sb}_{3.82} \mathrm{Sn}_{0.44} \mathrm{~S}_{13}$ also contain a second component with $\delta=0.62-0.63 \mathrm{~mm} / \mathrm{s}$ and $\Delta E_{\mathrm{Q}}=-(1.5-1.6) \mathrm{mm} / \mathrm{s}$. The values of hyperfine parameters well correspond to $\mathrm{Sn}^{4+}$, and the higher quadrupole splitting value compared to the main component indicates more distorted $\mathrm{Sn}$ in this second component. As evident from Rietveld refinement, this second component corresponds to an impurity phase of $\mathrm{Cu}_{3} \mathrm{Sb}_{0.63} \mathrm{Sn}_{0.47} \mathrm{~S}_{4}$ and $\mathrm{Cu}_{3} \mathrm{Sb}_{0.1} \mathrm{Sn}_{0.95} \mathrm{~S}_{4}$ in $\mathrm{Cu}_{11.17} \mathrm{Sb}_{3.85} \mathrm{Sn}_{0.35} \mathrm{~S}_{13}$ and $\mathrm{Cu}_{11.01} \mathrm{Sb}_{3.82} \mathrm{Sn}_{0.44} \mathrm{~S}_{13}$, respectively. The relative percentages of these two impurity phases were found to be 10.57 and $11.94 \%$, respectively, which is well validated by Rietveld refinement.

4.6. Transport Properties. 4.6.1. Electrical Resistivity ( $\rho)$. The electrical resistivities $(\rho)$ of the Sn-substituted samples $(x$ $=0.25,0.35,0.5$, and 1$)$ as a function of temperature are shown in Figure 7. The transport properties of $x=1.5$ samples are not shown due to a significant amount of secondary phases and inferior thermoelectric properties. It was observed that the electrical resistivity increased with increasing temperature, indicating degenerate semiconductor behavior. It was found that the substituted samples exhibited higher $\rho$ values across the measured temperature range compared to that of $\mathrm{Cu}_{12} \mathrm{Sb}_{4} \mathrm{~S}_{13}{ }^{8}$, indicating effective compensation of holes in

Table 2. Values of the Mössbauer Hyperfine Parameters ${ }^{a}$

\begin{tabular}{|c|c|c|c|c|c|c|}
\hline$x$ & phase & $\delta(\mathrm{mm} / \mathrm{s})$ & $\Delta E_{\mathrm{Q}}(\mathrm{mm} / \mathrm{s})$ & $W(\mathrm{~mm} / \mathrm{s})$ & RA (\%) & assignment \\
\hline \multirow[t]{3}{*}{0.5} & $\mathrm{Cu}_{11.17} \mathrm{Sb}_{3.85} \mathrm{Sn}_{0.35} \mathrm{~S}_{13}$ & 0.571 & 0.9835 & 1.0694 & 63.97 & $\mathrm{Sn}^{4+}$ \\
\hline & & 1.405 & 0.0408 & 0.9945 & 25.4 & $\mathrm{Sn}^{2+}$ \\
\hline & $\mathrm{Cu}_{3} \mathrm{Sb}_{0.63} \mathrm{Sn}_{0.47} \mathrm{~S}_{4}$ & 0.630 & -1.642 & 0.9613 & 10.57 & $\mathrm{Sn}^{4+}$ \\
\hline \multirow[t]{3}{*}{1} & $\mathrm{Cu}_{11.01} \mathrm{Sb}_{3.82} \mathrm{Sn}_{0.44} \mathrm{~S}_{13}$ & 0.569 & 1.001 & 1.0869 & 61.9 & $\mathrm{Sn}^{4+}$ \\
\hline & & 1.388 & 0.0206 & 0.9761 & 26.07 & $\mathrm{Sn}^{2+}$ \\
\hline & $\mathrm{Cu}_{3} \mathrm{Sb}_{0.1} \mathrm{Sn}_{0.95} \mathrm{~S}_{4}$ & 0.621 & -1.583 & 0.8764 & 11.94 & $\mathrm{Sn}^{4+}$ \\
\hline
\end{tabular}

${ }^{a}$ Derived from the fitting of the recorded room-temperature ${ }^{119} \mathrm{Sn}$ Mössbauer spectrum of the $\mathrm{Cu}_{12} \mathrm{Sb}_{4-x} \mathrm{Sn}_{x} \mathrm{~S}_{13}(x=0.5,1)$, where $\delta$ is the isomer shift, $\Delta E_{\mathrm{Q}}$ is the quadrupole splitting, $W$ is the full width at half-maximum, and RA is the relative spectral area of individual spectral components. 


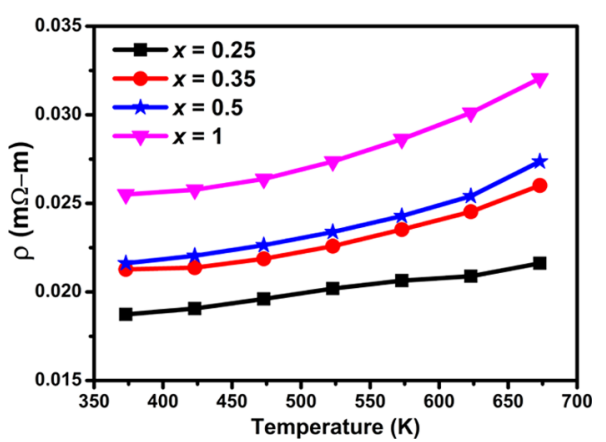

Figure 7. Electrical resistivity as a function of temperature for the samples $x=0.25,0.35,0.5$, and 1 .

the Sn-substituted samples because of $\mathrm{Sn}^{4+}$ substitution at $\mathrm{Cu}(1)^{1+} 12 \mathrm{e}$ site. It was observed that $\rho$ increased slightly with increasing $x$, but the increase is quite subtle, which could be due to $\mathrm{Sn}$ double substitution at both $\mathrm{Cu}(2) 12 \mathrm{e}$ and $\mathrm{Sb} 8 \mathrm{c}$ sites. Since $\mathrm{Sn}$ at $\mathrm{Sb}$ site may possess +2 oxidation state (as verified by XPS, DFT, and Mössbauer spectroscopy), it could supply holes to the system, and the combined effect may increase $\rho$ slightly, as elaborated in the theoretical Section 4.4. Another factor that can increase $\rho$ in $x=1$ sample is the enhanced charge carrier scattering from the interfaces of the secondary phase, leading to decrease in the charge carrier mobility and hence increase in $\rho$. To determine the charge carrier concentration and verify the above analysis, Hall measurements were performed for the samples. But unfortunately, a very low and inconsistent Hall voltage was observed in the samples, leading to inconclusive results.

4.6.2. Seebeck Coefficient (S). Figure 8 shows the Seebeck coefficient of the substituted samples $(x=0.25,0.35,0.5$, and

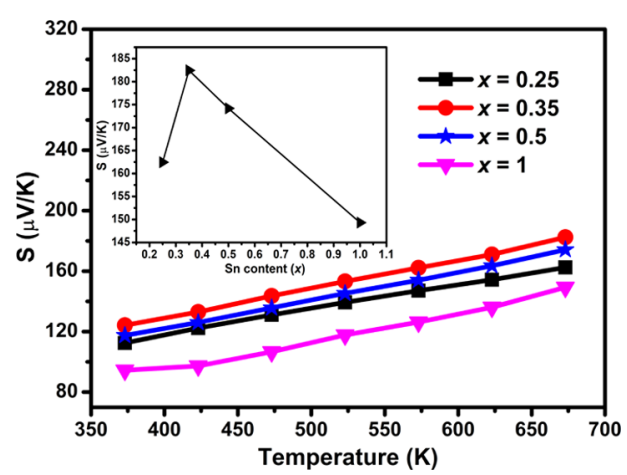

Figure 8. Seebeck coefficient as a function of temperature for the samples $x=0.25,0.35,0.5$, and 1 . The inset shows Seebeck coefficient as a function of $\mathrm{Sn}$ content at $673 \mathrm{~K}$.

1) as a function of temperature. The positive Seebeck coefficient throughout the temperature range of all of the samples indicates holes as the majority charge carriers. Comparing the Seebeck coefficient of the substituted samples with that of $\mathrm{Cu}_{12} \mathrm{Sb}_{4} \mathrm{~S}_{13}$, ${ }^{8}$ the substituted samples exhibited higher $S$ values due to effective hole compensation caused by Sn substitution. But the trend of $S$ with $x$ is not in accordance with the electrical resistivity results. The behavior of Seebeck coefficient in the substituted samples can be understood from Mott's formula given as

$$
S=\frac{\pi^{2}}{3} k_{\mathrm{B}}^{2} T\left[\frac{1}{n} \frac{\mathrm{d} n}{\mathrm{~d} E}+\frac{1}{\mu} \frac{\mathrm{d} \mu}{\mathrm{d} E}\right]_{E=E_{\mathrm{F}}}
$$

where $k_{\mathrm{B}}, n, \mu, T$, and $E_{\mathrm{F}}$ denote the Boltzmann constant, charge carrier concentration, charge carrier mobility, absolute temperature, and Fermi energy, respectively.

As can be seen from eq 2, the Seebeck coefficient depends on two factors: the first term has the factor $1 / n$ and a decrease in charge carrier concentration $(n)$ will increase the first term. But it also contains $\mathrm{d} n / \mathrm{d} E$, which is directly proportional to DOS near $E_{\mathrm{F}}$, and an increase in DOS (near $E_{\mathrm{F}}$ ) relates to an increase in $\mathrm{d} n / \mathrm{d} E$. It was observed from DFT calculations (Section 4.4) that $\mathrm{Sn}$ substituting at $\mathrm{Cu}$ compensates holes, resulting in an increase of the $1 / n$ factor. The Fermi level moves toward the band gap, and the DOS near $E_{\mathrm{F}}$ decreases as seen in Figure 5a,b for $\mathrm{Sn}$ substituting at $\mathrm{Cu}$, which should lead to a decrease in $\mathrm{d} n / \mathrm{d} E$. However, it was observed from Figure $5 \mathrm{~d}$,e that for $\mathrm{Sn}$ double substitution at $\mathrm{Cu}$ and $\mathrm{Sb}$, a finite DOS near $E_{\mathrm{F}}$ can arise due to hybridized hole states that can retain the $\mathrm{d} n / \mathrm{d} E$ term. And, it was established from the XRD and Mössbauer spectroscopy analysis that $\mathrm{Sn}$ may have substituted at both $\mathrm{Cu}(2) 12 \mathrm{e}$ and $\mathrm{Sb}$ sites. Therefore, the weightage of the first term in eq 2 depends on the relative concentration of $\mathrm{Sn}$ substitution at $\mathrm{Cu}(2) 12 \mathrm{e}$ and $\mathrm{Sb}$ sites. In the case of the second term (in eq 2 ), the $1 / \mu$ factor should increase when charge carrier mobility $(\mu)$ is low. Another contributing factor to the second term in eq 2 is $\mathrm{d} \mu / \mathrm{d} E$, which signifies the mobility dependence on energy. In other words, $\mathrm{d} \mu / \mathrm{d} E$ is affected when a scattering mechanism depends strongly on the energy of the charge carriers and thus may show a slight variation with $\mathrm{Sn}$ substitution. Hence, the second term in eq 2 is a combined effect of the charge carrier mobility and its energy dependence in the substituted samples.

The Seebeck coefficient of the Sn-substituted samples is therefore a complex function of the above-mentioned parameters. Consequently, the Seebeck coefficient of the substituted samples is higher than that of $\mathrm{Cu}_{12} \mathrm{Sb}_{4} \mathrm{~S}_{13}{ }^{8}$ because both the first and second terms of eq 2 are higher. The inset of Figure 7 shows a plot of Seebeck coefficient versus $x$ at $673 \mathrm{~K}$. It can be observed that the Seebeck coefficient (at $673 \mathrm{~K}$ ) first rises, achieves a maximum value for $x=0.35$, and then decreases for $x>0.35$. Assuming that $\mathrm{d} \mu / \mathrm{d} E$ is similar in these samples, the variation of Seebeck coefficient with $x$ should arise from the slight variation in charge carrier mobility $(\mu)$ and the difference in the relative weightages of the $1 / n$ and $\mathrm{d} n / \mathrm{d} E$ (DOS near $E_{\mathrm{F}}$ ) factors of the first term in eq 2 . In other words, if we consider the simplified Mott formula

$$
S=\frac{8 \pi^{2} k_{\mathrm{B}}^{2} T}{3 q h^{2}} m_{\mathrm{d}}^{*}\left(\frac{\pi}{3 n}\right)^{2 / 3}
$$

where $n$ is the charge carrier concentration and $m_{\mathrm{d}}^{*}$ is the DOS effective mass, the Seebeck coefficient scales as $1 / n^{2 / 3}$, whereas it is directly proportional to $m_{\mathrm{d}}^{*}$ (which is proportional to DOS near $E_{\mathrm{F}}$ and in turn depends on the relative occupancy of $\mathrm{Sn}$ substitution at $\mathrm{Cu}(2) 12 \mathrm{e}$ and $\mathrm{Sb}$ sites). Hence, the numerator $\left(m_{\mathrm{d}}^{*}\right)$ carries higher weightage in influencing the Seebeck coefficient compared to the denominator $\left(n^{2 / 3}\right)$. For $x \geq 0.5$ samples, although the effective charge carrier concentration (denominator of eq 3 ) decreases, it is offset by the numerator $\left(m_{\mathrm{d}}^{*}\right)$, which also decreases as $\mathrm{Sn}$ substitutes more at the $\mathrm{Cu}(2)$ $12 \mathrm{e}$ site (rather than $\mathrm{Sb}$ ) compared to samples with $x<0.5$, effectively resulting in a lower value of $m_{\mathrm{d}}^{*} / n^{2 / 3}$ ratio and hence 
lower Seebeck coefficient. The reason for Sn to prefer the $\mathrm{Cu}(2)$ site (at higher concentrations of $x$ ) can be inferred from the DFT results where it was explained that $\mathrm{Sn}^{4+}$ having a $4 \mathrm{~d}^{10}$ valence electronic configuration is relatively more stable at the $\mathrm{Cu}(2) 12 \mathrm{e}$ site rather than $\mathrm{Sn}^{2+}$ having $4 \mathrm{~d}^{10} 5 \mathrm{~s}^{2}$ configuration at $\mathrm{Sb}$ site. Moreover, as mentioned previously, the tetrahedrite system has been observed to be stable with compositions having a substituent that compensates holes and fills the valence band, ${ }^{15}$ such as $\mathrm{Sn}$ at $\mathrm{Cu}(2) 12 \mathrm{e}$ site in the present case. In addition, the effect of secondary phase should also be considered. It has been reported that the Seebeck coefficient of $\mathrm{Cu}_{3} \mathrm{Sb}_{1-y} \mathrm{Sn}_{y} \mathrm{~S}_{4}$ (secondary phase in the present series) decreases with increasing Sn content. ${ }^{21}$ For $x=0.5$ sample, there is relatively more $\mathrm{Sn}$ content (6 atom \%) in a total of 10 vol \% of $\mathrm{Cu}_{3} \mathrm{Sb}_{0.85} \mathrm{Sn}_{0.15} \mathrm{~S}_{4}$ secondary phase, whereas for $x=$ 0.25 and 0.35 , Sn content is around 1.8 and 3 atom $\%$ in a total of 6 and $7 \mathrm{vol} \%$ of secondary phase, respectively. Hence, for $x$ $=0.5$ sample, the Seebeck coefficient of the secondary phase may also play a role in affecting the overall Seebeck coefficient. This factor combined with the lower $m_{\mathrm{d}}^{*} / n^{2 / 3}$ ratio leads to Seebeck coefficient values of $x=0.5$ sample, intermediate to that of $x=0.25$ and 0.35 . The same argument also applies for $x$ $=1$ sample. But for $x=1$ sample, $\mathrm{Sn}$ substitutes at $\mathrm{Cu}(2)$ site even more (compared to $x<1$ samples), and the $m_{\mathrm{d}}^{*} / n^{2 / 3}$ ratio reduces even further. Combined with the fact that $\mathrm{Sn}$ content in the secondary phase is even higher (12 atom \%), the overall Seebeck coefficient of $x=1$ sample is lower than other samples. Another reason that can affect the variation of the $S$ versus $x$ trend could be differences in selective scattering of charge carriers due to differences in distribution and size of grain boundaries.

4.6.3. Power Factor $\left(S^{2} / \rho\right)$. Figure 9 displays the power factor (PF) of all of the samples $(x=0.25,0.35,0.5$, and 1$)$ as

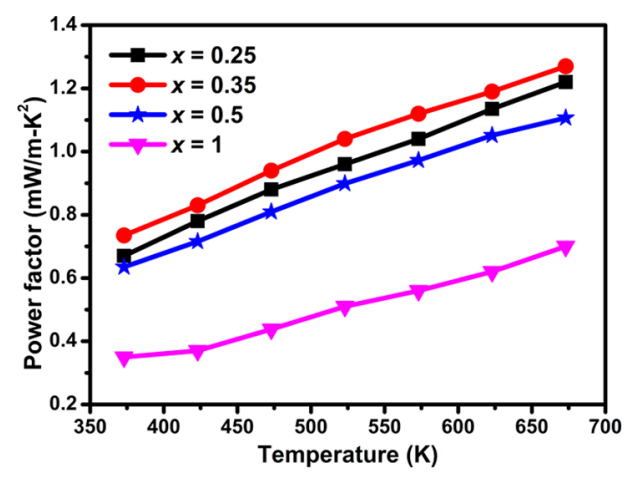

Figure 9. Power factor as a function of temperature for the samples $x$ $=0.25,0.35,0.5$, and 1 .

a function of temperature. Among the substituted samples, the maximum $\mathrm{PF} \sim 1.3 \mathrm{~mW} / \mathrm{mK}^{2}$ at $673 \mathrm{~K}$ was shown by $x=0.35$ sample due to relatively high Seebeck coefficient (124-182 $\mu \mathrm{V} / \mathrm{K})$ and low electrical resistivity $(0.021-0.026 \mathrm{~m} \Omega \mathrm{m})$ across the measured temperature range. This $\mathrm{PF}$ value is comparable to or higher than values obtained in the literature ${ }^{6,7,10-12,22,23}$ for single substitutions (for instance, $\sim 1.2 \mathrm{~mW} / \mathrm{mK}^{2}$ for $\mathrm{Cu}_{11.5} \mathrm{Zn}_{0.5} \mathrm{Sb}_{4} \mathrm{~S}_{13}{ }^{6}$ and $\mathrm{Cu}_{11.5} \mathrm{Mn}_{0.5} \mathrm{Sb}_{4} \mathrm{~S}_{13}$ at $673 \mathrm{~K}^{23} \sim 1.1 \mathrm{~mW} / \mathrm{mK}^{2}$ for $\mathrm{Cu}_{11.75} \mathrm{~Pb}_{0.25} \mathrm{Sb}_{4} \mathrm{~S}_{13}$ at $723 \mathrm{~K}^{28}$ ) and double substitutions $\left(\sim 0.5 \mathrm{~mW} / \mathrm{mK}^{2}\right.$ for $\mathrm{Cu}_{11.5} \mathrm{Ni}_{0.5} \mathrm{Sb}_{3.25} \mathrm{Te}_{0.75} \mathrm{~S}_{13}$ at $723 \mathrm{~K}^{11}$ and $\sim 1 \mathrm{~mW} / \mathrm{mK}^{2}$ for $\mathrm{Cu}_{11} \mathrm{Zn}_{1} \mathrm{Sb}_{4} \mathrm{~S}_{12.5} \mathrm{Se}_{0.5}$ at $673 \mathrm{~K}^{12}$ ) in tetrahedrite, including the recently reported Sn-substituted series $\mathrm{Cu}_{12-x} \mathrm{Sn}_{x} \mathrm{Sb}_{4} \mathrm{~S}_{13}{ }_{13}$ $\left(\sim 1.1 \mathrm{~mW} / \mathrm{mK}^{2}\right.$ at $\left.665 \mathrm{~K}\right)$. On the other hand, the minimum PF was obtained for $x=1$ sample due to relatively large electrical resistivity across the measured temperature range. It can be concluded that $\mathrm{Sn}$ double substitution in low concentrations $(x \leq 0.5)$ at the two Wycoff positions of $\mathrm{Cu}(2) 12 \mathrm{e}$ and $\mathrm{Sb} 8 \mathrm{c}$ sites in tetrahedrite can be beneficial for enhancement of the power factor. This is due to the fact that $\mathrm{Sn}^{4+}$ at $\mathrm{Cu}(2) 12 \mathrm{e}$ and $\mathrm{Sn}^{2+}$ at $\mathrm{Sb}$ sites effectively lead to only a slight increase in electrical resistivity with $x$ but also retain a relatively moderate Seebeck coefficient. As a result, a reasonably high power factor could be achieved in $x \leq 0.5$ samples.

4.6.4. Thermal Conductivity $(\kappa)$. Figure 10 shows the temperature-dependent total thermal conductivity $\left(\kappa_{\mathrm{T}}\right)$ of all of

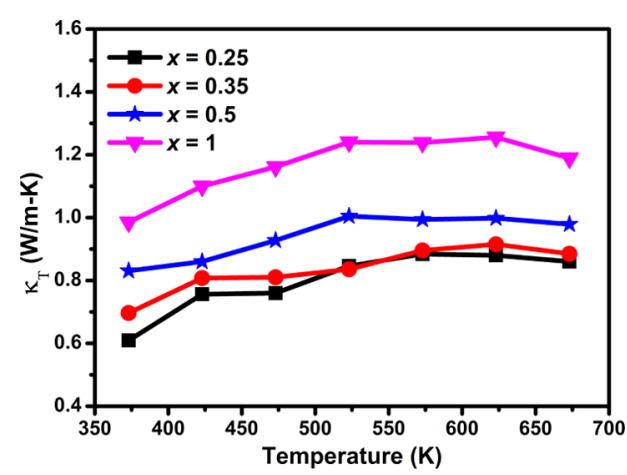

Figure 10. Total thermal conductivity as a function of temperature for the samples $x=0.25,0.35,0.5$, and 1 .

the samples $(x=0.25,0.35,0.5$, and 1$)$. The total thermal conductivity consists of electronic $\left(\kappa_{\mathrm{e}}\right)$ and lattice $\left(\kappa_{\mathrm{L}}\right)$ components. The electronic component of the thermal conductivity $\left(\kappa_{\mathrm{e}}\right)$ was evaluated from the Wiedemann-Franz relation given by

$$
\kappa_{\mathrm{e}}=\frac{L T}{\rho}
$$

where $L$ represents the temperature-dependent Lorenz number, $T$ is the temperature, and $\rho$ denotes the electrical resistivity. The Lorenz number $L$ can be written as

$$
L=\left(\frac{k_{\mathrm{B}}}{e}\right)^{2}\left(\frac{\left(r+\frac{7}{2}\right) F_{\mathrm{r}+5 / 2}(\eta)}{\left(r+\frac{3}{2}\right) F_{\mathrm{r}+1 / 2}(\eta)}-\left[\frac{\left(r+\frac{5}{2}\right) F_{\mathrm{r}+3 / 2}(\eta)}{\left(r+\frac{3}{2}\right) F_{\mathrm{r}+1 / 2}(\eta)}\right]^{2}\right)
$$

where $\eta=E_{\mathrm{F}} / k_{\mathrm{B}} T$ denotes the reduced Fermi energy and was calculated from Seebeck coefficient values via the equation

$$
S= \pm \frac{k_{\mathrm{B}}}{e}\left(\frac{\left(r+\frac{5}{2}\right) F_{\mathrm{r}+3 / 2}(\eta)}{\left(r+\frac{3}{2}\right) F_{\mathrm{r}+1 / 2}(\eta)}-\eta\right)
$$

$F(\eta)$ denotes the reduced Fermi integral evaluated as

$$
F_{n}(\eta)=\int_{0}^{\infty} \frac{x^{n}}{1+\mathrm{e}^{x-\eta}} \mathrm{d} x
$$

Considering that the major scattering mechanism in the samples is acoustic phonon scattering, $r$ was considered as -1 / 2 . From the known Seebeck coefficient values, $\eta$ was deduced from eq 6. Finally, the temperature-dependent Lorenz number 
(L) was evaluated at each temperature by substituting $r$ and $\eta$ in eq 5 . The electronic thermal conductivity, $\kappa_{\mathrm{e}}$ was then obtained by substituting $L$ in eq 4 . The lattice thermal conductivity $\left(\kappa_{\mathrm{L}}\right)$ was calculated by subtracting $\kappa_{\mathrm{e}}$ from $\kappa_{\mathrm{T}}$ according to the equation $\kappa_{\mathrm{T}}=\kappa_{\mathrm{e}}+\kappa_{\mathrm{L}}$. Figures 11 and 12 show the plots of $\kappa_{\mathrm{e}}$ and $\kappa_{\mathrm{L}}$ as a function of temperature, respectively.

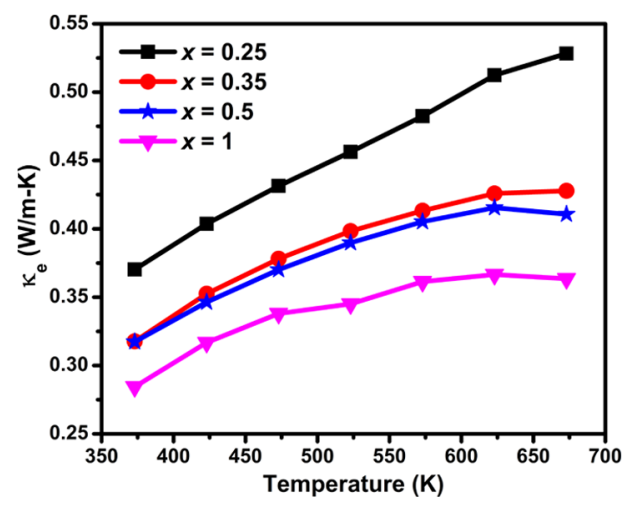

Figure 11. Carrier thermal conductivity as a function of temperature for the samples $x=0.25,0.35,0.5$, and 1 .

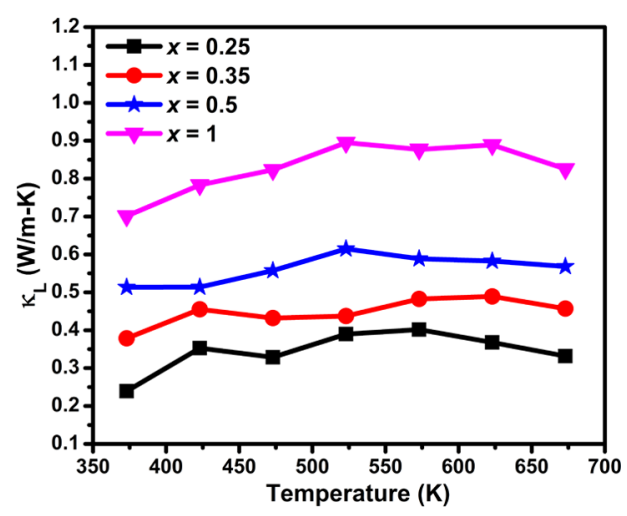

Figure 12. Lattice thermal conductivity as a function of temperature for the samples $x=0.25,0.35,0.5$, and 1 .

The total thermal conductivity of the Sn-substituted samples was found to be lower than that of $\mathrm{Cu}_{12} \mathrm{Sb}_{4} \mathrm{~S}_{13}$. ${ }^{8}$ This is due to the effective charge carrier compensation (causing reduction in $\kappa_{\mathrm{e}}$ ) and higher phonon scattering (because of $\mathrm{Sn}-\mathrm{Cu}$ and $\mathrm{Sn}-$ $\mathrm{Sb}$ mass difference) in the substituted samples compared to $\mathrm{Cu}_{12} \mathrm{Sb}_{4} \mathrm{~S}_{13}$. It was found that $\kappa_{\mathrm{e}}$ decreased with increase in $\mathrm{Sn}$ content, due to effective compensation of holes in the Snsubstituted samples because of $\mathrm{Sn}^{4+}$ substitution at $\mathrm{Cu}(2) 12 \mathrm{e}$ site, as explained in the electrical resistivity Section 4.6.1. The decrease in $\kappa_{\mathrm{e}}$ with $x$ thus follows inversely with the electrical resistivity trend according to eq 4 . However, it was observed that the total thermal conductivity increased with $x$ primarily due to increase in the lattice thermal conductivity of the substituted samples with $x$ as seen from Figure 12. The intrinsically low values of lattice thermal conductivity in tetrahedrite arise due to the large anharmonic out-of-plane oscillations of the $\mathrm{Cu}(2)$ atoms, caused by the lone pair electrons on $\mathrm{Sb}$ situated on either side of the $\mathrm{Cu}(2)$ atoms. This results in a localized low-energy mode perpendicular to the $\mathrm{CuS}_{3}$ triangle plane. Consequently, this localized mode scatters the high-velocity acoustic phonons (the main carriers of heat) and hybridizes with the acoustic dispersions leading to a reduction in thermal conductivity due to reduced group velocities. ${ }^{24}$ But it was shown by May et al. ${ }^{25}$ that with a divalent substituent such as $\mathrm{Zn}$ in $\mathrm{Cu}_{11} \mathrm{Zn}_{2} \mathrm{Sb}_{4} \mathrm{~S}_{13}$, the charge carrier concentration decreases (due to compensation of holes by $\mathrm{Zn}^{2+}$ at $\mathrm{Cu}^{1+}$ site), leading to suppression of electronic screening of the atomic displacements. As a result, the localized low-energy mode perpendicular to the $\mathrm{CuS}_{3}$ plane stiffens and the structure is stabilized. Similarly, in the present case, the increase in $\kappa_{\mathrm{L}}$ with $x$ could be due to the suppression of out-ofplane anharmonic vibration of the $\mathrm{Cu}(2)$ atoms because of $\mathrm{Sn}$ substitution at the $\mathrm{Cu}(2) 12 \mathrm{e}$ and $\mathrm{Sb}$ sites. As the $\mathrm{Sn}$ content $(x)$ increases, this effect becomes more pronounced, thereby leading to increase in lattice thermal conductivity. Another factor could be a stronger covalent overlap of the Sn orbitals with the host atoms that can relatively mediate a higher phonon movement. A similar behavior was also observed in $\mathrm{Zn}$ and Se double-substituted samples, where a higher Se bond covalency resulted in an increase in the lattice component of thermal conductivity. ${ }^{12}$ The other factors for a high $\kappa_{\mathrm{L}}$ in $x=1$ sample could be the influence of secondary phase in the sample with a high $\mathrm{Sn}$ content $\left(\mathrm{Cu}_{3} \mathrm{Sb}_{0.1} \mathrm{Sn}_{0.95} \mathrm{~S}_{4}\right)$, which possesses a relatively higher thermal conductivity ${ }^{21}$ compared to the main tetrahedrite phase.

4.6.5. Thermoelectric Figure of Merit (zT). The dimensionless thermoelectric figure of merit of all of the substituted samples as a function of temperature is shown in Figure 13.

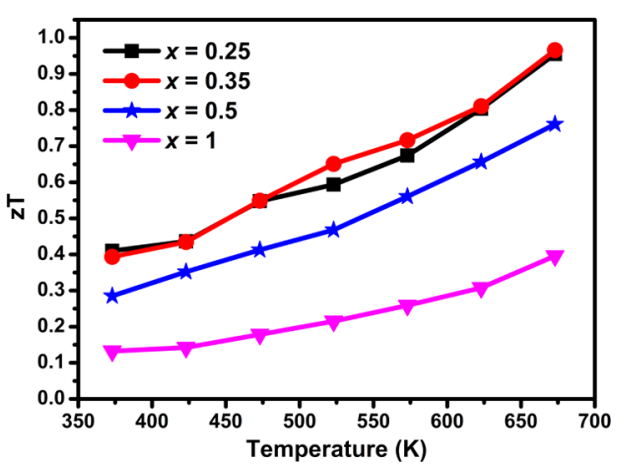

Figure 13. Thermoelectric figure of merit as a function of temperature for the samples $x=0.25,0.35,0.5$, and 1 .

Although Sn substitution caused an increase in electrical resistivity and could not improve the power factor compared to $\mathrm{Cu}_{12} \mathrm{Sb}_{4} \mathrm{~S}_{13}\left(1.45 \mathrm{~mW} / \mathrm{mK}^{2}\right.$ at $\left.673 \mathrm{~K}^{8}\right)$, a significant reduction of thermal conductivity was obtained in the present series. As a result, the maximum $z T$ of 0.96 at $673 \mathrm{~K}$ was shown by the $x=$ 0.35 sample primarily due to suppressed total thermal conductivity $(0.88 \mathrm{~W} / \mathrm{mK}$ at $673 \mathrm{~K})$. This $z T$ value is comparable to or higher than values in the literature ${ }^{6-12,26-28}$ for single substitutions (e.g., 0.7 for $\mathrm{Cu}_{10.5} \mathrm{Ni}_{1.5} \mathrm{Sb}_{4} \mathrm{~S}_{13}$ at $665 \mathrm{~K}^{7}$ and 0.8 at $623 \mathrm{~K}$ for $\left.\mathrm{Cu}_{12} \mathrm{Sb}_{4-x} \mathrm{Te}_{x} \mathrm{~S}_{13}{ }\right)$ and double substitutions ( 0.8 obtained for $\mathrm{Cu}_{11.18} \mathrm{Co}_{0.82} \mathrm{Sb}_{3.59} \mathrm{Te}_{0.41} \mathrm{~S}_{13}$ at $673 \mathrm{~K}^{10}$ and 0.7 for $\mathrm{Cu}_{11.5} \mathrm{Ni}_{0.5} \mathrm{Sb}_{3.25} \mathrm{Te}_{0.75} \mathrm{~S}_{13}$ at $673 \mathrm{~K}^{11}$ ) in tetrahedrite. The current $z T$ value is also higher than that obtained for $\mathrm{Sn}$-substituted $\mathrm{Cu}_{12-x} \mathrm{Sn}_{x} \mathrm{Sb}_{4} \mathrm{~S}_{13}$ series investigated by Kosaka et al., where the highest $z T$ of 0.65 was achieved at $665 \mathrm{~K}$ for $x=0.3-0.5$. $^{13}$ Therefore, it was noted that a significant enhancement of $z T$ can be attained in tetrahedrite with small Sn concentrations ( $x<0.5$ per formula unit) doubly occupying the $\mathrm{Cu}(2) 12 \mathrm{e}$ and $\mathrm{Sb}$ sites.

4.6.6. Compatibility Factor (s). Apart from having a reasonably high $z T$, the compatibility factor of the material is 
also important in determining the overall efficiency of a segmented thermoelectric device or generator. Since different materials exhibit maximum $z T$ s at different operating temperatures, the efficiency of a practical device over a large temperature range can be maximized using segmented legs of different materials, which should have compatibility factor within a factor of 2 . The compatibility factor $(s)$ of the Snsubstituted samples $(x=0.25,0.35,0.5$, and 1$)$ as a function of

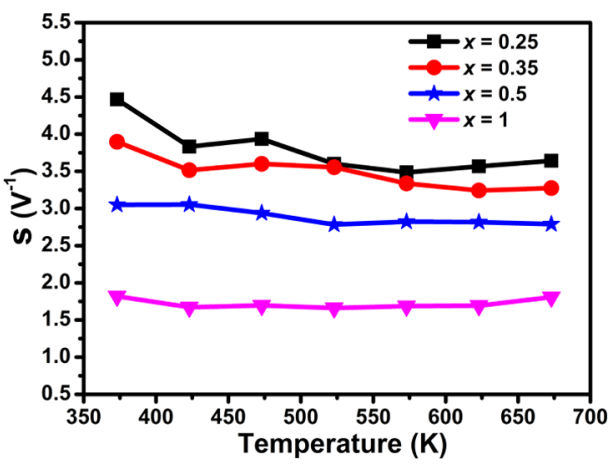

Figure 14. Compatibility factor as a function of temperature for the Sn-substituted samples $(x=0.25,0.35,0.5$, and 1$)$.

temperature is shown in Figure 14, calculated using the following equation ${ }^{29}$

$$
s=\frac{\sqrt{1+z T}-1}{S T}
$$

where $z$ is the thermoelectric figure of merit, $S$ is the Seebeck coefficient, and $T$ is the temperature. It was observed from Figure 13 that all of the samples exhibit an almost unchanged $s$ with temperature, which is beneficial for a segmented assembly in a thermoelectric device. The $x=0.35$ sample exhibiting the highest $z T$ among the $S n$-substituted samples has $s$ values between 3.8 and $3.2 \mathrm{~V}^{-1}$ across the measured temperature range. These values are within a factor of 2 compared to other high-performing p-type materials such as $\mathrm{Yb}_{14} \mathrm{MnSb}_{12}$, TAGS, $\mathrm{CeFe}_{4} \mathrm{Sb}_{12}$, ${ }^{30}$ and $\mathrm{PbTe}_{0.7} \mathrm{~S}_{0.3}$. ${ }^{31}$ In conclusion, the near invariance of compatibility factor with temperature coupled with its similar magnitude compared to other materials makes Sn-substituted samples potential candidates for device applications.

\section{CONCLUSIONS}

In summary, a detailed investigation was performed in the present study to understand the effect of Sn substitution in tetrahedrite. It was found from a combined analysis of XRD, XPS, DFT, and Mössbauer spectroscopy that Sn exists in mixed valency of +4 and +2 and substituting at both $\mathrm{Cu}(2)$ $12 \mathrm{e}$ and $\mathrm{Sb} 8 \mathrm{c}$ sites. The DFT analysis revealed that $\mathrm{Sn}$ at $\mathrm{Cu}(2) 12 \mathrm{e}$ site compensates holes and moves the Fermi level toward the band gap, whereas $\mathrm{Sn}$ at $\mathrm{Sb} 8 \mathrm{c}$ site introduces hole states near $E_{\mathrm{F}}$. Therefore, a trade-off between these two effects determined the overall transport properties. Based on characterization and electrical resistivity results, it was found that $\mathrm{Sn}$ has a higher preference for $\mathrm{Cu}(2) 12 \mathrm{e}$ site but also substituted at $\mathrm{Sb}$ site in small concentrations. Effectively, the charge carrier compensation increased with $x$ only slightly leading to a slight increment in the electrical resistivity. But a relatively moderate DOS near $E_{\mathrm{F}}$ was retained, resulting in a significant increase in the Seebeck coefficient in the substituted samples (compared to $\mathrm{Cu}_{12} \mathrm{Sb}_{4} \mathrm{~S}_{13}$ ). The thermal conductivity of the substituted samples could be reduced primarily due to reduced electronic thermal conductivity. As a result, a maximum $z T$ of 0.96 at $673 \mathrm{~K}$ was achieved for $x=0.35$ sample. It can be concluded that $\mathrm{Sn}$ has the interesting property of exhibiting dual oxidation states and therefore could substitute at two different Wycoff positions in the crystal unit cell of tetrahedrite. As a result, a double-substitution scenario could be achieved using only one kind of substituent, which also facilitates cost-effectiveness in material preparation. Coupled with a favorable compatibility factor over the measured temperature range, the $\mathrm{Sn}$-substituted samples $(x<$ 0.5 p.f.u.) can be suitable for device applications. The present work also opens up the possibility of performing similar studies in other ternary chalcogenides with group 14 element substitution.

\section{ASSOCIATED CONTENT}

\section{Supporting Information}

The Supporting Information is available free of charge on the ACS Publications website at DOI: 10.1021/acsami.9b02956.

Refinement parameters with $\mathrm{Sn}$ substituted at various Wycoff positions for $x=0.25$ and 1 samples (Tables S1 and S2); lattice parameter with $\mathrm{Sn}(x)$ content (Table S3); XPS peak assignment of $\operatorname{Sn} 3 \mathrm{~d}_{5 / 2}$ in $x=0.25$ and 1 samples (Table S4); refined XRD patterns of all of the Sn-substituted samples $(x=0.25,0.35,0.5,1,1.5)$ (Figures S1-S5) (PDF)

\section{AUTHOR INFORMATION}

\section{Corresponding Author}

*E-mail: rcmallik@iisc.ac.in.

ORCID $\odot$

Ramesh Chandra Mallik: 0000-0002-8383-7812

\section{Notes}

The authors declare no competing financial interest.

\section{ACKNOWLEDGMENTS}

The authors acknowledge Department of Science and Technology (DST), India, for financial support through grant no - EEQ/2018/000036. The DST-FIST program is also acknowledged for providing XPS experimental facility.

\section{REFERENCES}

(1) Gelbstein, Y.; Dashevsky, Z.; Dariel, M. P. High Performance ntype PbTe-Based Materials for Thermoelectric Applications. Phys. B 2005, 363, 196-205.

(2) Heremans, J. P.; Jovovic, V.; Toberer, E. S.; Saramat, A.; Kurosaki, K.; Charoenphakdee, A.; Yamanaka, S.; Snyder, G. J. Enhancement of Thermoelectric Efficiency in PbTe by Distortion of the Electronic Density of States. Science 2008, 321, 554-557.

(3) Yamashita, O.; Tomiyoshi, S.; Makita, K. Bismuth Telluride Compounds with High Thermoelectric Figures of Merit. J. Appl. Phys. 2003, 93, 368-374.

(4) Zhang, Q.; Chere, E. K.; Sun, J.; Cao, F.; Dahal, K.; Chen, S.; Chen, G.; Ren, Z. Studies on Thermoelectric Properties of n-type Polycrystalline $\mathrm{SnSe}_{1-\mathrm{x}} \mathrm{S}_{\mathrm{x}}$ by Iodine Doping. Adv. Energy Mater. 2015, 5, No. 1500360.

(5) Zhao, L. D.; Tan, G.; Hao, S.; He, J.; Pei, Y.; Chi, H.; Wang, H.; Gong, S.; Xu, H.; Dravid, V. P.; Uher, C.; Snyder, G. J.; Wolverton, C.; Kanatzidis, M. G. Ultrahigh Power Factor and Thermoelectric 
Performance in Hole-Doped Single-Crystal SnSe. Science 2016, 351, 141-144.

(6) Lu, X.; Morelli, D. T.; Xia, Y.; Zhou, F.; Ozolins, V.; Chi, H.; Zhou, X.; Uher, C. High Performance Thermoelectricity in EarthAbundant Compounds Based on Natural Mineral Tetrahedrites. Adv. Energy Mater. 2013, 3, 342-348.

(7) Suekuni, K.; Tsuruta, K.; Kunii, M.; Nishiate, H.; Nishibori, E.; Maki, S.; Ohta, M.; Yamamoto, A.; Koyano, M. High-performance Thermoelectric Mineral $\mathrm{Cu}_{12-\mathrm{x}} \mathrm{Ni}_{\mathrm{x}} \mathrm{Sb}_{4} \mathrm{~S}_{13}$ Tetrahedrite. J. Appl. Phys. 2013, 113, No. 043712.

(8) Chetty, R.; Bali, A.; Naik, M. H.; Rogl, G.; Rogl, P.; Jain, M.; Suwas, S.; Mallik, R. C. Thermoelectric Properties of Co Substituted Synthetic Tetrahedrite. Acta Mater. 2015, 100, 266-274.

(9) Bouyrie, Y.; Canolfi, C.; Ohorodniichuk, V.; Malaman, B.; Dauscher, A.; Tobola, J.; Lenoir, B. Crystal Structure, Electronic Band Structure and High-Temperature Thermoelectric Properties of TeSubstituted Tetrahedrites $\mathrm{Cu}_{12} \mathrm{Sb}_{4-\mathrm{x}} \mathrm{Te}_{\mathrm{x}} \mathrm{S}_{13}(0.5 \leq \mathrm{x} \leq 2.0)$. J. Mater. Chem. C 2015, 3, 10476-10487.

(10) Bouyrie, Y.; Sassi, S.; Candolfi, C.; Vaney, J. B.; Dauscher, A.; Lenoir, B. Thermoelectric Properties of Double-Substituted Tetrahedrites $\mathrm{Cu}_{12-\mathrm{x}} \mathrm{Co}_{\mathrm{x}} \mathrm{Sb}_{4-\mathrm{y}} \mathrm{Te}_{\mathrm{y}} \mathrm{S}_{13}$. Dalton Trans. 2016, 45, 7294-7302.

(11) Bouyrie, Y.; Candolfi, C.; Vaney, J. B.; Dauscher, A.; Lenoir, B. High Temperature Transport Properties of Tetrahedrite $\mathrm{Cu}_{12-\mathrm{x}} \mathrm{M}_{\mathrm{x}} \mathrm{Sb}_{4-\mathrm{y}} \mathrm{Te}_{\mathrm{y}} \mathrm{S}_{13}(\mathrm{M}=\mathrm{Zn}, \mathrm{Ni})$ Compounds. J. Electron. Mater. 2016, 45, 1601-1605.

(12) Tippireddy, S.; Chetty, R.; Raut, K. K.; Naik, M. H.; Mukharjee, P.; Jain, M.; Nath, R. C.; Wojciechowski, K. T.; Mallik, R. C. Electronic and Thermoelectric Properties of $\mathrm{Zn}$ and Se Double Substituted Tetrahedrite. Phys. Chem. Chem. Phys. 2018, 20, 2866728677.

(13) Kosaka, Y.; Suekuni, K.; Hashikuni, K.; Bouyrie, Y.; Ohta, M.; Takabatake, T. Effects of Ge and Sn Substitution on the MetalSemiconductor Transition and Thermoelectric Properties of $\mathrm{Cu}_{12} \mathrm{Sb}_{4} \mathrm{~S}_{13}$ Tetrahedrite. Phys. Chem. Chem. Phys. 2017, 19, 88748879.

(14) Nasonova, D. I.; Sobolev, A. V.; Presniakov, I. A.; Andreeva, K. D.; Shevelkov, A. V. Position and Oxidation State of Tin in Sn-bearing Tetrahedrites $\mathrm{Cu}_{12-\mathrm{x}} \mathrm{Sn}_{\mathrm{x}} \mathrm{Sb}_{4} \mathrm{~S}_{13}$. J. Alloys Compd. 2019, 778, 774-778. (15) Hansen, M. K.; Makovicky, E.; Karup-Møller, S. Exploratory Studies on Substitutions in Tetrahedrite-Tennantite Solid Solution. Part IV. Substitution of Germanium and Tin. Neues Jahrb. Mineral., Abh. 2003, 179, 43-71.

(16) Rodriguez-Carvajal, J. In FULLPROF: A Program for Rietveld Refinement and Pattern Matching Analysis, Abstracts of the Satellite Meeting on Powder Diffraction of the XV Congress of the IUCr, 1990; p 127.

(17) Giannozzi, P.; Baroni, S.; Bonini, N.; Calandra, M.; Car, R.; Cavazzoni, C.; Ceresoli, D.; Chiarotti, G. L.; Cococcioni, M.; Dabo, I.; Corso, A. D.; de Gironcoli, S.; Fabris, S.; Fratesi, G.; Gebauer, R.; Gerstmann, U.; Gougoussis, C.; Kokalj, A.; Lazzeri, M.; MartinSamos, L.; Marzari, N.; Mauri, F.; Mazzarello, R.; Paolini, S.; Pasquarello, A.; Paulatto, L.; Sbraccia, C.; Scandolo, S.; Sclauzero, G.; Seitsonen, A. P.; Smogunov, A.; Umari, P.; Wentzcovitch, R. M. QUANTUM ESPRESSO: A Modular and Open-Source Software Project for Quantum Simulations of Materials. J. Phys.: Condens. Mater. 2009, 21, No. 395502.

(18) Perdew, J. P.; Burke, K.; Ernzerhof, M. Generalized Gradient Approximation Made Simple. Phys. Rev. Lett. 1996, 77, 3865-3868.

(19) Shannon, R. D. Revised Effective Ionic Radii and Systematic Studies of Interatomic Distances in Halides and Chalcogenides. Acta Crystallogr., Sect. A: Found. Adv. 1976, 32, 751-767.

(20) Wells, A. F. Structural Inorganic Chemistry, 5th ed.; Clarendon Press: Oxford, 1984.

(21) Chen, K.; Paola, C. D.; Du, B.; Zhang, R.; Laricchia, S.; Bonini, N.; Weber, C.; Abrahams, I.; Yan, H.; Reece, M. Enhanced Thermoelectric Performance of Sn-doped $\mathrm{Cu}_{3} \mathrm{SbS}_{4}$. J. Mater. Chem. C 2018, 6, 8546-8552.

(22) Bouyrie, Y.; Candolfi, C.; Dauscher, A.; Malaman, B.; Lenoir, B. Exsolution Process as a Route toward Extremely Low Thermal
Conductivity in $\mathrm{Cu}_{12} \mathrm{Sb}_{4-\mathrm{x}} \mathrm{Te}_{\mathrm{x}} \mathrm{S}_{13}$ Tetrahedrites. Chem. Mater. 2015, 27, 8354-8361.

(23) Chetty, R.; Prem Kumar, D. S.; Rogl, G.; Rogl, P.; Bauer, E.; Michor, H.; Suwas, S.; Puchegger, S.; Giester, G.; Mallik, R. C. Thermoelectric Properties of a Mn Substituted Synthetic Tetrahedrite. Phys. Chem. Chem. Phys. 2015, 17, 1716-1727.

(24) Lara-Curzio, E.; May, A. F.; Delaire, O.; McGuire, M. A.; Lu, X.; Liu, C.-Y.; Case, E. D.; Morelli, D. T. Low-temperature Heat Capacity and Localized Vibrational Modes in Natural and Synthetic Tetrahedrites. J. Appl. Phys. 2014, 115, No. 193515.

(25) May, A. F.; Delaire, O.; Niedziela, J. L.; Lara-Curzio, E.; Susner, M. A.; Abernathy, D. L.; Kirkham, M.; McGuire, M. A. Structural Phase Transition and Phonon Instability in $\mathrm{Cu}_{12} \mathrm{Sb}_{4} \mathrm{~S}_{13}$. Phys. Rev. B 2016, 93, No. 064104

(26) Tippireddy, S.; Chetty, R.; Naik, M. H.; Jain, M.; Chattopadhyay, K.; Mallik, R. C. Electronic and Thermoelectric Properties of Transition Metal Substituted Tetrahedrites. J. Phys. Chem. C 2018, 122, 8735-8749.

(27) Kumar, D. S. P.; Chetty, R.; Femi, O. E.; Chattopadhyay, K.; Malar, P.; Mallik, R. C. Thermoelectric Properties of Bi Doped Tetrahedrite. J. Electron. Mater. 2016, 46, 2616-2622.

(28) Huang, L. L.; Wang, Y. S.; Zhu, C.; Xu, R.; Li, J. M.; Zhang, J. H.; Li, D.; Wang, Z. M.; Wang, L.; Song, C. J.; Xin, H. X.; Zhang, J.; Qin, X. Y. Preparation and Enhanced Thermoelectric Performance of $\mathrm{Pb}$-doped Tetrahedrite $\mathrm{Cu}_{12-\mathrm{x}} \mathrm{Pb}_{\mathrm{x}} \mathrm{Sb}_{4} \mathrm{~S}_{13}$. J. Alloys Compd. 2018, 769, 478-483.

(29) Snyder, G. J.; Ursell, T. S. Thermoelectric Efficiency and Compatibility. Phys. Rev. Lett. 2003, 91, No. 148301.

(30) Brown, S. R.; Kauzlarich, S. M.; Gascoin, F.; Snyder, G. J. $\mathrm{Yb}_{14} \mathrm{MnSb}_{11}$ : New high Efficiency Thermoelectric Material for Power Generation. Chem. Mater. 2006, 18, 1873-1877.

(31) Ouyang, Z.; Li, D. Modelling of Segmented High Performance Thermoelectric Generators with Effects of Thermal Radiation, Electrical and Thermal Contact Resistances. Sci. Rep. 2016, 6, No. 24123. 